\title{
Antecedentes arquitectónicos patrimoniales del departamento del atlántico
}

\section{Architectural heritage background of the department of atlantico}

\author{
DOI: 10.17981/mod.arq.cuc.22.1.2019.01
}

Artículo. Fecha de Recepción: 02/15/2019. Fecha de Aceptación: 03/15/2019.

\section{Jairo Lopez Martinez}

Universidad de la Costa (Colombia)

jlopez@cuc.edu.co

Para citar este artículo:

López. J. (2019). Antecedentes arquitectónicos patrimoniales del departamento del Atlántico, MODULO ARQUITECTURA CUC, vol. 22, no. 1, pp. 9-48, 2019. DOI: http:// doi.org/10.17981/mod.arq.cuc.22.1.2019.01

\section{Resumen}

El estudio del desarrollo de los pueblos, y el estado de conservación de su patrimonio constituye un tema de suma importancia, ya que ayuda a conocer, entre otras cosas, las formas de vida de un lugar y la identidad cultural de sus gentes en un momento específico. Se plantea el estudio de los antecedentes arquitectónicos patrimoniales en el departamento del Atlántico, en el caso concreto del patrimonio edificado, que permita dar a conocer no solo el grado de mantenimiento de las estructuras que forman parte de éste, sino explorar las diversas maneras de entender el entorno, con base en factores como su morfología y tipología. Algunos municipios en el Sur del departamento del Atlántico se han visto afectados a partir de la catástrofe natural ocurrida por la hora invernal en el año 2011, lo cual ha ocasionado un fuerte impacto no solo en el estado de las edificaciones, sino en el ámbito socio-económico, generando la desesperanza en una comunidad arraigada a un lugar, que comúnmente se organiza en torno a un espacio público flanqueado por una unidad religiosa y edificios administrativos, rodeados por numerosas viviendas, lo cual se podría traducir en una morfología urbana propia de una actividad programada y estandarizada de la colonización española. El estudio de los antecedentes arquitectónicos patrimoniales en el departamento del Atlántico es pensado con el ánimo, de que provean a las administraciones municipales, de una herramienta que sirva de apoyo para solicitar de acuerdo a las Normas y Criterios del Ministerio de Cultura, la asignación de recursos para los Programas de Restauración y el Mantenimiento de Monumentos Nacionales que lleva a cabo la Dirección de Patrimonio.

Palabras clave: Conservación; patrimonio; antecedentes; morfología; tipología; socio-económico; Normas, Criterios; Restauración; Mantenimiento; Monumentos.

\begin{abstract}
The study of the development of peoples and the state of conservation of their heritage is an extremely important subject, since it helps to know, among other things, the ways of life of a place and the cultural identity of its people at a specific time. The study of the architectural heritage antecedents in the department of Atlántico is proposed, in the specific case of built heritage, which allows not only to know the degree of maintenance of the structures that form part of it, but also to explore the different ways of understanding the environment, based on factors such as its morphology and typology. Some municipalities in the South of the department of Atlántico have been affected from the natural catastrophe occurred by the winter hour in 2011, which has caused a strong impact not only in the state of the buildings, but in the socio-economic field, generating hopelessness in a community rooted in a place, which is commonly organized around a public space flanked by a religious unit and administrative buildings, surrounded by numerous houses, which could translate into an urban morphology typical of a programmed and standardized activity of the Spanish colonization. The study of the architectural heritage antecedents in the department of Atlántico is designed with the intention of providing municipal administrations with a tool that serves as support to request, in accordance with the Norms and Criteria of the Ministry of Culture, the allocation of resources for the Programs of Restoration and Maintenance of National Monuments carried out by the Directorate of Heritage.
\end{abstract}

Keywords: Conservation; heritage; history; morphology; typology; socio-economic; standards; criteria; restoration; maintenance; monuments. 


\section{INTRODUCCIÓN}

\section{Marco Teórico y Normativo}

Los municipios constituyen piezas fundamentales para el estudio de los antecedentes arquitectónicos patrimoniales en el departamento del atlántico; en ellos podemos encontrar elementos de alto valor histórico y ambiental. Sin embargo la preservación de éstos es cada día más difícil debido a factores como el abandono y la degradación física y económica, la poca identificación y valoración por parte de la comunidad y el limitado apoyo de las instituciones locales.

Para el desarrollo de este estudio, se hace necesario, además del personal antes citado, de la concientización y participación comunitaria por cuanto constituye un factor determinante en la preservación de las acciones a ser acometidas, al igual que en las definición de criterios y prioridades de la intervención misma. El estudio tiene como finalidad específica, descubrir e identificar con criterio profesional, todos aquellos elementos patrimoniales ocultos y dispersos, que al ser analizados e intervenidos puntualmente, coadyuven al diseño de estrategias de actuación para el mejoramiento de la calidad del espacio público en los municipios del departamento del Atlántico, y a la vez impulsando la implementación de una serie de estudios técnicos especializados para la recuperación, rehabilitación y conservación de los mismos, además de una estrategia concertada en la recuperación de la memoria colectiva de los pueblos. La pertinencia del proyecto radica en la falta de un estudio que se convierta en una herramienta para los organismos municipales, que ayude a presentar propuestas de declaratoria de las manifestaciones y tradiciones culturales, así como también los listados de los bienes inmuebles de uso doméstico candidatos a ser declarados Bienes de Interés Cultural del Departamento del Atlántico. Como recurso cultural-patrimonial, los bienes de interés cultural deben ser valorados, conservados, protegidos y capitalizados en su más justo y equilibrado peso, de manera sistemática y contextual (Tello, 2013).

Ahora bien, el estudio, se fundamenta en los conceptos y lineamientos establecidos en los Documentos Internacionales sobre Patrimonio Arquitectónico, en los cuales se define que las obras monumentales de cada pueblo son el testimonio vivo de sus tradiciones, es decir son portadoras de un mensaje espiritual del pasado.

El monumento es inseparable de la historia de la cual es testigo, y también del medio en el cual está situado. La restauración tiene como fin conservar y revelar los valores estéticos e históricos de un monumento y se fundamenta en el respeto hacia los elementos antiguos y las partes auténticas. Los monumentos de interés arqueológico, histórico y artístico constituyen también recursos económicos al igual que las riquezas naturales de los municipios; las medidas conducentes a su preservación y adecuada utilización deben formar parte de los planes de desarrollo. 
Es esencial que los estudios y trabajos de los antecedentes arquitectónicos patrimoniales, sean puestos en conocimiento de las autoridades responsables a nivel departamental (Consejo Departamental de Cultura y Patrimonio), con el fin de elaborar las recomendaciones de acuerdo a los estados de estos elementos patrimoniales y promover la adopción de las medidas necesarias para su valoración y conservación. En efecto, se trata de dirigir los esfuerzos locales en el sentido de procurar el mejor aprovechamiento de los recursos monumentales de que se disponga, como medio indirecto de favorecer el desarrollo económico de los municipios en el departamento del Atlántico.

Poner en valor el patrimonio arquitectónico de los municipios del departamento del Atlántico, equivale a habilitarlos de las condiciones objetivas y ambientales, que sin desvirtuar su naturaleza, resaltan sus características y permiten su óptimo aprovechamiento. Esta puesta en valor se debe realizar en función de contribuir al desarrollo económico de los municipios. Buscar que del seno de las comunidades aparezca la voz de alarma y la acción vigilante y previsora; el fomento de agrupaciones cívicas pro defensa del patrimonio en localidades que no disponen aún de regulación del mismo, y donde la acción protectora del estado resulta débil o no es eficaz por la falta de conocimiento de la existencia de este patrimonio, es uno de los tantos vacíos que se quieren llenar con este estudio.
Nada puede contribuir mejor a la toma de conciencia que se procura, que la contemplación del ejemplo propio. Una vez se aprecian los resultados de ciertas obras de restauración y conservación de edificaciones patrimoniales, plazas y lugares, suele operarse una buena reacción ciudadana que paraliza la acción destructora y permite la consecución de los objetivos.

Planear el trazado del recorrido por los distintos municipios del departamento del Atlánti$\mathrm{co}$, incluyendo los corregimientos, en los cuales bajo una investigación previa sobre la existencia de posibles elementos que podrían declararse monumentos arquitectónicos patrimoniales y/o culturales, servirá para trazar el itinerario con relación al tiempo destinado para la ejecución del estudio. Diez (10) horas semanales de investigación representaron jornadas de fin de semana que comprometieron traslados y visitas a diferentes sitios para descubrir, describir y avanzar en el nivel teórico de la argumentación científica y crítica para la lectura de los objetos arquitectónicos patrimoniales.

Por otro lado, para el manejo y conservación del patrimonio cultural colombiano se deben tener en cuenta los elementos normativos establecidos en la Constitución Política del 1991, en la Ley 397 de 1997 (Ley General de Cultura), y en la Ley 1185 de 2008, que modifica y adiciona, entre otros, el título II de la Ley 397 de 1997, que trata temas relacionados con el patrimonio cultural. 


\section{Constitución Política de 1991}

La Carta Política vigente afirmó el papel de la cultura como fundamento de la nacionalidad, al considerarla una dimensión especial de desarrollo, un derecho de la sociedad y una instancia que identifica a Colombia como país multiétnico y pluricultural. La Constitución garantiza los derechos culturales y proporciona los marcos para el desarrollo legislativo del sector" (República de Colombia. Ministerio de Cultura, 2009).

Los artículos 7, 8, 63, 70, 71 y 72 de la Constitución (1991) contemplan, en lo que respecta al patrimonio cultural, la protección, que compete tanto al Estado como a los particulares, la libertad esencial que debe proyectarse en la búsqueda del conocimiento y la expresión artística, la propiedad exclusiva y pública de la nación sobre determinados bienes culturales y la obligación estatal de incentivar la creación y la gestión cultural.

\section{Ley 1185 de 2008}

La Ley 1185 (2008), que modifica y adiciona la Ley General de Cultura y dicta otras disposiciones, deja en claro que los bienes del patrimonio cultural de la nación declarados bienes de interés cultural (BIC) pueden pertenecer, según el caso, a la nación, a entidades públicas de cualquier orden o a personas naturales o jurídicas de derecho privado, y reconoce el derecho de las iglesias y confesiones religiosas a ser propietarias del patrimonio cultural que hayan creado o adquirido.
Asimismo establece el Sistema Nacional de Patrimonio Cultural, conformado por el conjunto de instancias y procesos de desarrollo institucional, planificación e información articulados entre sí, lo cual posibilita la protección, recuperación, conservación, sostenibilidad y divulgación del patrimonio cultural de la nación.

Reorganiza y actualiza la competencia sobre el patrimonio arqueológico, que recae en el Instituto Colombiano de Antropología e Historia, y se destaca que su propiedad es exclusiva del Estado, de conformidad con los artículos 63 y 72 de la Constitución Política (1991), que consagra que los bienes del patrimonio arqueológico pertenecen a la nación, son inalienables, imprescriptibles e inembargables.

Se crea el Consejo Nacional de Patrimonio Cultural, que sustituye al Consejo de Monumentos Nacionales como órgano encargado de asesorar al gobierno Nacional sobre la salvaguardia, protección y el manejo de patrimonio cultural de la nación. Igualmente se crean los consejos departamentales y distritales de patrimonio cultural, cuyo objetivo es cumplir, respecto de los BIC del ámbito territorial respectivo, funciones análogas a las del Consejo Nacional de Patrimonio Cultural.

Se establece la inembargabilidad, imprescriptibilidad e inalienabilidad de los bienes de interés cultural de entidades públicas. El Ministerio de Cultura, en el caso de los BIC del ámbito nacional, y las entidades territoriales, en el de los respectivos bienes declarados por ellas, quedan facultados para autorizar la enajenación o préstamo de dichos bienes entre entidades públicas. Así mismo pueden autorizar a las entidades públicas propietarias de BIC 
para darlos en comodato a entidades privadas sin ánimo de lucro, celebrar convenios interadministrativos, de asociación y, en general, para celebrar cualquier tipo de contrato, incluido el de concesión, que implique la entrega de dichos bienes a particulares, siempre que cualesquiera de las modalidades que se utilicen se dirija a promover y garantizar la protección y conservación de estos bienes.

Se establece un régimen especial de protección de los bienes de interés cultural, que recoge en gran medida lo establecido en el artículo 11 de la Ley 397 de 1997, pero se enfatiza en materia del Plan Especial de Manejo y Protección (PEMP), instrumento de planeación por medio del cual se salvaguardan y preservan los BIC y se garantiza su protección y sostenibilidad en el tiempo. Igualmente, se establecen norma sobre intervención, enajenación y exportación de estos bienes.

\section{Desarrollo}

\section{Hacia una propuesta de itinerarios para la valorización del patrimonio arquitectónico en el departamento del Atlántico}

Para identificar, los elementos arquitectónicos patrimoniales es necesario tener en cuenta una serie de elementos conceptuales que coadyuven a precisar con claridad la elaboración del proceso. A continuación se relacionan en orden de importancia:

\section{Patrimonio}

Por Patrimonio Arquitectónico se puede entender un edificio, conjunto de edificios o las ruinas de un edificio, o de un conjunto de edificios, que con el paso del tiempo, ha adquirido un valor mayor al originalmente asignado y que va mucho más allá del encargo original. Este valor, como lo señalan los capítulos de ICOMOS, puede ser cultural o emocional, físico o intangible, histórico o técnico.

El concepto de "Patrimonio Arquitectónico", está inmerso en el de Patrimonio Cultural, sin embargo, el primero se refiere, casi exclusivamente a las obras de arquitectura que dicen tener relación con la identidad y la memoria de un lugar. Las obras de arquitectura que pueden ser consideradas de Patrimonio Arquitectónico, serán entonces las que debido a una multiplicidad de razones, no todas ellas técnicas o artísticas, se consideran que sin ellas, el entorno donde se ubican, dejaría de ser lo que es.

\section{Tipología}

Se denomina tipología a ciertos elementos que comprenden una misma función, o que representan un conglomerado de construcciones que se definen por un mismo estilo.

\section{Criterio de Intervención}

Norma, regla o pauta para conocer la verdad o la falsedad de una cosa. 


\section{Clasificación de la Arquitectura según las Tipologías}

No todas las arquitecturas son iguales ya que no todas responden a las mismas necesidades. Suele hacerse una clasificación de tres tipos de arquitectura a saber:

\section{- Arquitectura histórica o estilística}

Para los historiadores del arte, la arquitectura se reduce a aquellas obras que toman en cuenta el espacio y los lenguajes artísticos con lo cual se limitan a estudiar una selección de arquitectura clave especialmente significativas dentro del desarrollo de la historia del arte.

\section{- Arquitectura popular o tradicional}

Definir la arquitectura popular plantea dificultades, se puede establecer una distinción entre la arquitectura vernácula y la arquitectura primitiva. Las diferencias entre ambas están dada por el diferente grado de complejidad técnica. La arquitectura primitiva tiende a la definición territorial con rituales, mientras que la arquitectura popular busca en primer lugar la solución óptima de la función. Así mismo, las características de la Arquitectura popular o tradicional tienen que ver con: el protagonismo de los materiales y de las técnicas constructivas de la zona. La participación directa del usuario en el proyecto y en su realización. El empleo de un repertorio formal sencillo con algunas referencias a los lenguajes cultos. La perfecta adecuación a las necesidades funcionales.

\section{- Arquitectura común o vulgar}

Existe una arquitectura que no puede ser considerada ni histórica ni popular. Es aquella cuyo único objetivo es la utilidad sin ningún tipo de vínculo con la arquitectura histórica ni pretensiones artísticas. Es la arquitectura vulgar solamente utilitaria que llena las ciudades. Estas diferencias no han existido siempre sino para cada época histórica han tenido sus propias concepciones de la arquitectura y su diferencia con la simple construcción.

\section{- Arquitectura Domestica}

En contraste con la arquitectura religiosa y civil de carácter monumental, se encuentra la arquitectura doméstica: la típica casa antigüeña que se caracteriza por su desarrollo en una sola planta, la cual basa la distribución de sus habitaciones alrededor de uno o más patios centrales, en donde es muy común encontrar búcaros que con su rumor de agua transmiten tranquilidad y frescura a los diferentes ambientes. Alrededor de estos patios, sus anchos y frescos corredores sirven como complemento a las áreas sociales que se abren a estos espacios, siempre dispuestos a facilitar una tertulia. Contrario a la abertura de los espacios interiores de las casas en donde se desarrolla la vida familiar, nos encontramos con fachadas exteriores, compuestas de ventanales altos con balcones de herrería, que pautan un límite del exterior público hacia la intimidad de la vivienda. 
dos cualidades esenciales: una visión estratégica general para planear con lógica militar la defensa de una ciudad y un talento práctico o poder de organización y mando para ejecutar las obras en forma rápida y eficiente.

\section{- Arquitectura Colonial}

Las características de la arquitectura colonial en Colombia están marcadas por su condición de colonia con una economía de subsistencia, donde la explotación de oro y plata no jugó el importante papel que tuvo en Nueva España (México) o Perú, joyas de la corona española.

\section{- Arquitectura Republicana}

Caracterizada por el detalle en la decoración, contagiada por el espíritu romántico francés y asociada a una élite burguesa. Arquitectura Republicana con influencia La Transición: Art Deco- Art Nouveau.

\section{Ornamento}

Un ornamento es un elemento o composición que sirve para embellecer personas o cosas. El variadísimo conjunto de adornos utilizados por los artistas para embellecer objetos u obras arquitectónicas puede considerarse de dos clases: simples (o elementales) y compuestos. Los primeros consisten en un solo motivo, ya aislado, ya repetido y combinado con otro en serie. Los segundos, son una combinación de los elementales. Los adornos simples se dividen a su vez en:

\section{- Geométricos}

Compuestos por líneas de la geometría. Se dividen en dos tipos: a) El de la línea continua que constituye la moldura; b) El de línea interrumpida o adorno geométrico simplemente dicho;

\section{- Orgánicos}

Los orgánicos, según sean, seres del reino vegetal o animal. Se denominan respectivamente fitaria y zoodaria.

\section{Motivos de relieves y volúmenes}

Son los elementos que le dan a las fachadas una riqueza de ornamentación, ayudan a resaltar los volúmenes y detalles de las piezas decorativas, y van desde el bajo, medio y alto relieve; elaborados en morteros de yeso, cemento y piedra; y se pueden clasificar tres grupos:

\section{- Zoomorfos}

Estos motivos se basan en el empleo de distintas especies animales, los principales y los más utilizados de la fauna ornamental fueron el león, podría ser de cuerpo entero, las cabezas de león, cabezas de perros, palomas, toros, peces, águilas, conchas, todos estos de diversidad de formas y perfiles.

\section{- Antropomorfos}

Es la representación de la figura humana empleada en el arte decorativo, los más comunes, son los rostros femeninos, mascarones, figuras de hombres 
con aspectos de rudeza, y algo grotesco, efigies, medallones, cabezas de ángeles y arcángeles alados y medias figuras.

\section{- Fitomorfos}

El reino vegetal sin duda fue el recurso ornamental más empleado, y con mayores representaciones de las artes decorativas, las formas más interpretadas fueron las hojas flores frutos ramas y tallos, el motivo más utilizado fue la planta de acanto en toda su variedad de formas y tamaños, Otro motivo empleado con gran destreza fueron los modelos de ramajes y volutas y zarcillos, lirios, laurel, ramas con frutos, helechos, palmas, trigos, rosas, azucenas, entre otras.

\section{Balcón}

Es una especie de plataforma que se proyecta desde la pared de un edificio, sostenido por columnas o ménsulas, y cerrado mediante unas balaustradas.

\section{Balaustradas}

La balaustrada clásica es una herencia del renacimiento, donde eran dispuestas en balcones y escaleras, utilizadas en arquitectura palladiana para definir la línea horizontal del tejado en algunas ocasiones interrumpidas con estatuas y urnas.

\section{Pilastras}

Estos elementos se usaban para articular tanto los muros exteriores como los interiores. Podían ser sencillas, estriadas, animadas y decoradas.

\section{Arcos Ciegos}

Elementos usados para articular la superficie de los muros. Son depresiones de poca profundidad en forma de arco, usadas especialmente en el exterior de las edificaciones, por lo general alrededor de las ventanas y puertas, y en algunos casos eran dispuestas para romper con la simplicidad de grandes extensiones de paramento sencillo.

\section{Remate}

Complementa el volumen principal, el remate posee características ornamentales de excelente lenguaje y variado repertorio ornamental clásico. Los remates ocultan la cubierta, y estos pueden estar compuestos por entablamentos, frisos, balaustradas, y en algunos casos por frontones circulares, semicirculares, o triangulares.

\section{Valoración del Patrimonio}

Desde la axiología (rama de la filosofía que estudia la teoría del valor) se define la valoración a partir de criterios: atributos que son reconocidos en el bien cultural y que permiten describirlo, ponderarlo y entenderlo. De acuerdo con Tello (2008):

La valoración patrimonial como acto que se centra en la protección. Permite como punto de partida la elaboración de inventarios de patrimonio. En este caso, es importante subrayar la importancia que para una sociedad tiene el identificar y proteger sus bienes de interés cultural. Para esto la elaboración de inventarios de dichos bienes 
implica procedimientos valorativos que buscan no solo identificar sino comprender, jerarquizar, clasificar y evaluar de manera individualizada y en conjunto, aquellos bienes, construcciones, conjuntos, sectores urbanos y demás objetos patrimoniales, que por su valor deben ser protegidos. El fin del inventario será listar los bienes de interés cultural, protegerlos con un tratamiento de conservación, lo que además se sustenta en las políticas y deriva en normas y adicionalmente, evaluar su estado de conservación y/o deterioro, con el fin de definir los criterios de intervención y las acciones según prioridades (Tello, 2008).

La clasificación tipológica de las edificaciones encontradas en el itinerario cultural por los Municipios del Departamento del Atlántico, se establecen bajo parámetros generales, y criterios estéticos, compositivos y funcionales; analizándolas y clasificándolas, según las cuatro tipologías tradicionales o históricas como son: Arquitectura Colonial, Arquitectura Republicana, Arquitectura de Transición y Arquitectura Moderna.

\section{La Valoración}

Los criterios de valoración son pautas generales que orientan y contribuyen a la atribución y definición del significado cultural de un bien mueble o inmueble. El valor cultural de cualquier edificación permite que ésta pueda ser protegida mediante una declaratoria de Bien de Interés Cultural, con la respectiva inscripción en el Régimen Especial de Protección o de Salvaguarda previsto en la ley, según los siguientes criterios:

\section{Antigüedad}

Determinada por la fecha o época de origen, fabricación o construcción del bien.

\section{Autoría}

Identificación del autor, autores o grupo que hayan dejado testimonio de su producción, asociada a una época, estilo o tendencia. La autoría puede ser, excepcionalmente, atribuida.

\section{Autenticidad}

Determinada por el estado de conservación del bien y su evolución en el tiempo. Se relaciona con su constitución original y con las transformaciones e intervenciones derivadas, las cuales deben ser claramente legibles. Las transformaciones o alteraciones de la estructura original no deben desvirtuar su carácter.

\section{Constitución del bien}

Se refiere a los materiales y a las técnicas constructivas o de elaboración.

\section{Forma}

Se relaciona con los elementos compositivos y ornamentales del bien con respecto a su origen histórico, su tendencia artística estilística o de diseño, con el propósito de reconocer su utilización y sentido estético. 


\section{Estado de conservación}

Condiciones físicas del bien plasmadas en los materiales, estructura, espacialidad o volumetría, entre otros. Entre las condiciones que lo determinan se encuentra el uso, cuidados y mantenimiento del bien.

\section{Contexto ambiental}

Se refiere a la constitución e implantación del bien en relación con el ambiente y el paisaje.

\section{Contexto urbano}

tiene que ver con la inserción del bien, como unidad individual, en un sector urbano consolidado. Se deben analizar características como: perfil, diseño, acabados, color, volumetría, elementos urbanos, organización y llenos y vacíos.

\section{Contexto físico}

Se refiere a la relación del bien con su lugar de ubicación. Analiza su contribución a la conformación y desarrollo de un sitio, población o paisaje. Si el bien se encuentra dentro de un inmueble, debe analizarse si fue concebido como parte integral de éste y/o si ha sido asociado con un nuevo uso y función relevantes dentro del inmueble.

\section{Representatividad y contextualización sociocultural}

Hace referencia a la significación cultural que tiene el bien en la medida que crea lazos emocionales entre la sociedad y los objetos y sitios. Revela el sentido de pertenencia de un grupo humano sobre los bienes de su hábitat, toda vez que implica referencias colectivas de memoria e identidad.

\section{Los Posibles Itinerarios Arquitectónicos Patrimoniales.}

Los recorridos o itinerarios culturales se trazaron de acuerdo a los ejes viales del departamento del Atlántico, teniendo en cuenta tres zonas a saber:

\section{Eje Occidental: Sentido Norte - Sur}

Comprende el barrido de los municipios con sus respectivos corregimientos localizados a lo largo de la vía al Mar: Municipio de Puerto Colombia (corregimientos de Sabanilla, Salgar); Municipio de Juan de Acosta (corregimientos de Boca Tocino, Chorrera, San José de Saco y Santa Verónica); Municipio de Tubará (corregimientos de El Morro, Cuatro Bocas, Guaimaral, Juaruco); Municipio de Piojó (corregimientos de Aguas Vivas; Cerrito e Ibácharo).

\section{Municipio de Puerto Colombia}

Localizado al norte del departamento de Atlántico, y a unos $18 \mathrm{~km}$ de la ciudad de Barranquilla, hace parte del Área metropolitana del distrito de Barranquilla; con una extensión de $93 \mathrm{~km}^{2}$ y a una altura de 5 metros sobre el nivel del mar, comprende los corregimientos de Salgar, Sabanilla y Monte Carmelo. A pesar de estar localizado a orillas del mar, el municipio es 
bordeado por las faldas del cerro Cupino, Nisperal, la Risota y Pan de Azúcar. Hasta aqui llegó la primera vía ferrea que se construyo en el pais y contribuyó a la expansión del mercado colombiano a nivel internacional (Palacio et al., 2011).

\section{Patrimonio Nacional}

Castillo de San Antonio de Salgar (ubicado en e corregimiento de Salgar a diez (10) minutos de la ciudad de Barranquilla). Joya arquitectónica considerada monumento historico y cultural del departamento. Declarado BIC mediante resolución 0799 de Julio de 1998 . Fue construido para funcionar como

Aduana, en 1848. Entre la lista de usos a lo largo de defensa, cárcel, sede de un colegio y de un instituto para personas discapacitadas. En sus primeros años fue el fuerte de SanAntonio, y servia para el percate de la llegada de tropas extranjeras en la época de la colonia. Décadas despues de ser derrumbado -en el siglo XVII- los españoles construyeron lo que hoy día se aprecia, con parametros arquitectónicos coIoniales. En el año 1876 la Aduana fue trasladada a fun a de la ciudad de Barranquilla y poco a poco se ue abandonando el sitio.

\section{$1+$}

$1 x_{i}-200$

inners

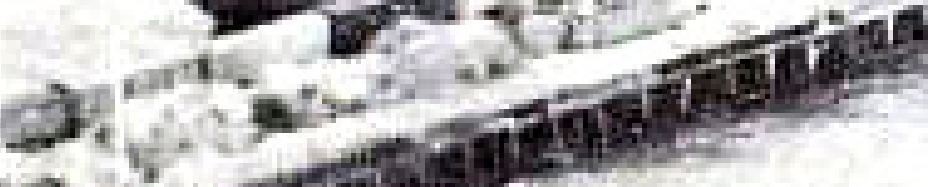

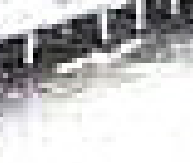
mo

\begin{abstract}
$\rightarrow$ ins
\end{abstract}

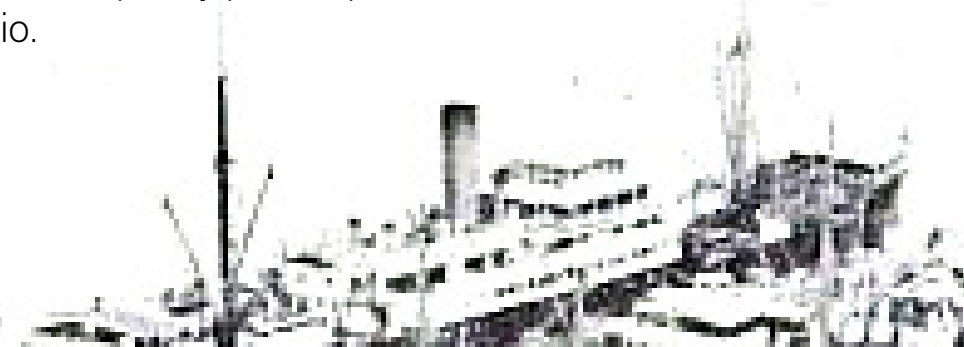

\section{- Muelle de Puerto Colombia}

"La primera salida al mar que tuvo Barranquilla en el siglo XIX fue la bahía de Sabanilla, primer puerto

La comunicacion era a traves del Caño de la Piña,

que comunicaba a Barranquilia cơn Sabanilla donde

ción del Ferrocarril de Bolivar en Enero de 1871, es-

ta vía acuática dejo de ser utilizada. Inicialmente el

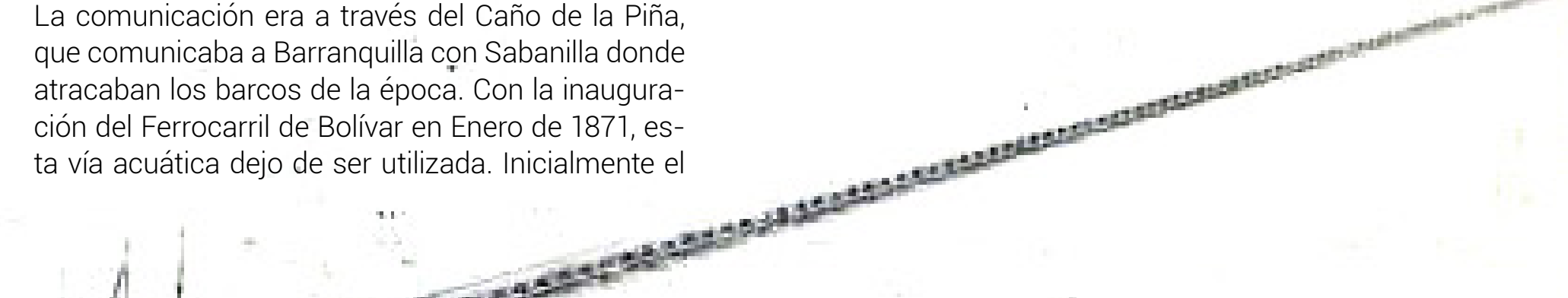

importante de comercio exterior que tuvo Colombia.

atracaban los barcos de la epoca. Con la inaugura- ferrocarril iba desde el puerto fluvial de Barranquilla hasta Sabanilla, luego se prolongó hasta Salgar y finalmente hasta Puerto Colombia, to que dio origen a la construcción del Muelle de Puerto Colombia en Figura 1. Foto Muelle de Puerto Colombia en 1920.
Fuente: skyscrapercity.com, varielandia. wikispaces.com. Francisco Javier Cisneros
Entre los años 1871 y 1920 Barranquilla se consolida como paso obligado del comercio exterior coPuerto Co a través de la conexión con el muelle de minara la Primera Guerra Mundial y abrieran el canal de Panamá, comenzó a funcionar el puerto de Buenaventura, por donde las exportaciones comenlian desce Puerto Colombia fue entonces cuando en Barranquilla (1936) decidieron hacer el súper puerto y desde ese momento comenzó el triste final del muelle de Puerto Colombia, y en 1943 se extinguió la vida del primer puerto marítimo de Colombia (Ovalle, El 7 de marzo de 2009 se caen los primeros 200 me-
tros lineales del muelle 
- Edificaciones patrimoniales con caracteristicas tipológicas

El Santuario Mariano de Nuestra Señora del Carmen (Iglesia de Puerto Colombia); La Iglesia de Salgar; Edificio de la Antigua Alcaldía de Puerto Colombia (construido en 1928, arquitectura Republicana); la Antigua Estación del Ferrocarril Barranquilla (construido por trabajadores de "The Railway \& Pier Co" Ingeniero Francisco Cisneros; el Cementerio Municipal y las Construcciones correspondientes a la arquitectura doméstica.

A la zona ubicada al norte de la Estación del Ferrocarril Bolívar y a orillas de la playa en Puerto Colombia se formó el sector hotelero, en donde hoy se encuentran las edificaciones del Hotel Esperia, Hotel Estambul, Hotel Viña del Mar y restos o ruinas del Hotel Pargo Rojo, los cuales unos han cambiado de uso, otros atienden al turismo social popular algunos permanecen intactos en su estado de conservación, otros han sido intervenidos y sus detalles se muestran en las fichas de inventario.

Municipio de Juan de Acosta

Su fundación data de principios del siglo XVII (1606), por colonos de la provincia de Cartagena, recibe la calidad de municipio según la ordenanza 052 de agosto del año 1892, por la asamblea de Bolívar. Su nombre proviene de San Jual ta. Situado a $40 \mathrm{~km}$ de la ciudad de Barranquilla, a oeste del departamento; sus corregimientos son Boca Tocino, Chorrera, San José de Saco y Santa Verónica.
Figura 2. Foto Casa de Palma de la Familia Higgins.

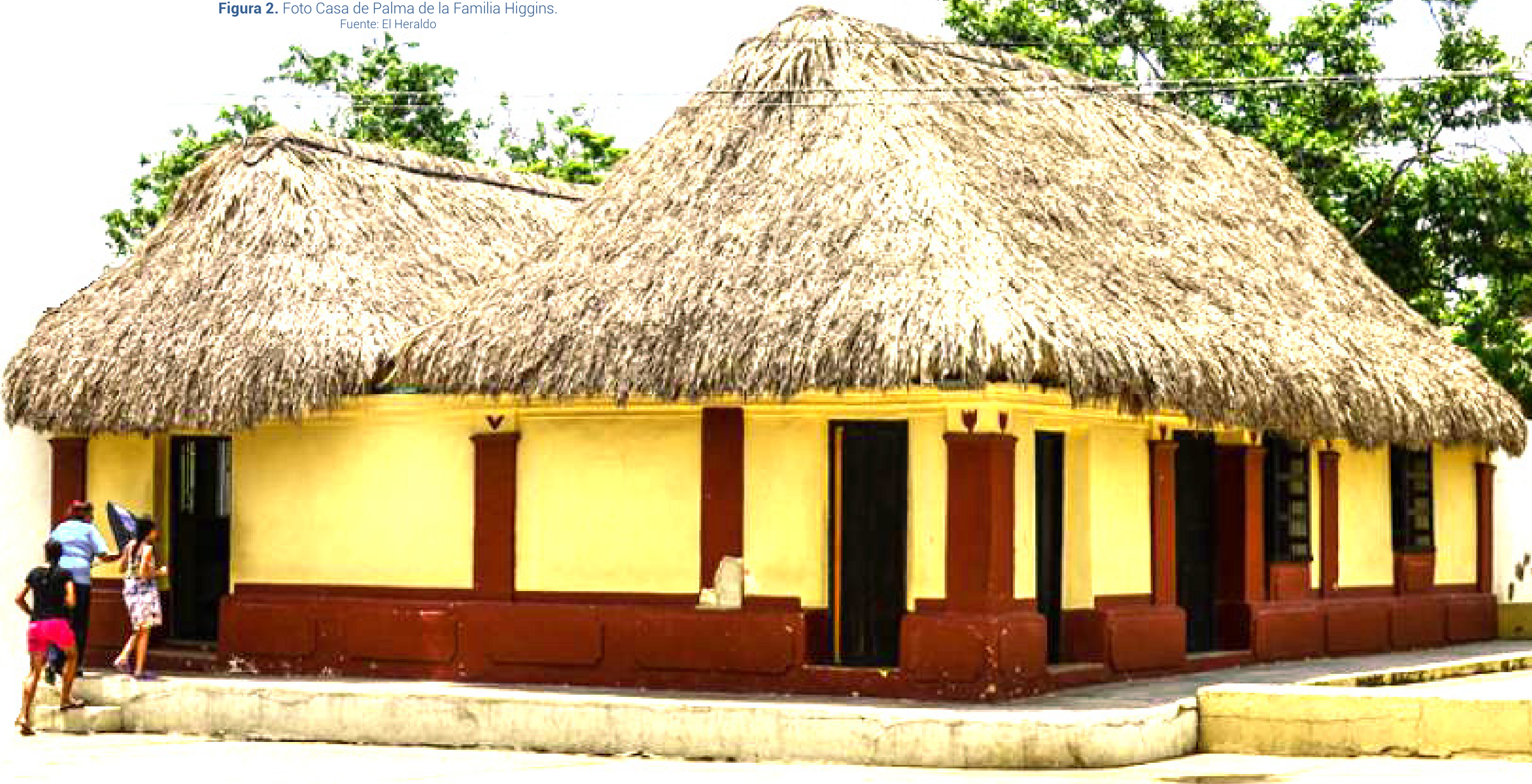

3.6.t. (1)

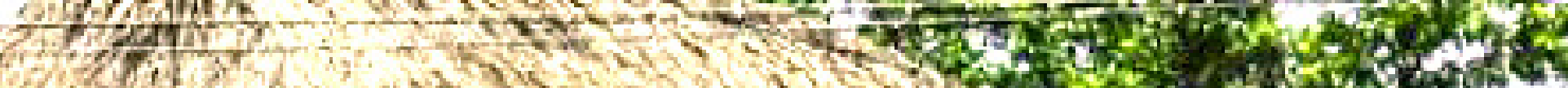


La arquitectura característica de la población se fundamenta en construcciones de bahareque paredes de barro y cubiertas en palma o paja, muy a pesar de la influencia española estas edificaciones no presentan rasgos de arquitectura colonial.

- Casa de Palma de la Familia Higgins

- Arroyo gallego - mural del pintor Alejandro Obregón en el cementerio

\section{Municipio de Tubará}

De origen precolombino, descubierto como caserío indígena por Don Pedro de Heredia en el año 1533. Esta población tenía título de resguardo indígena de las leyes españolas desde el año 1611. Su nombre indica sitio de reunión (indigenas Cipacua y yaguaro), y proviene de Ztupará (voz arawak que significa mirando hacia el mar - etnia mokana). Construcciones indigenas (piedra pintada), arte rupestre mokaná en el corregimiento de Morro, sobre el lecho del arroyo camajorú (sinología zoomorfay antropomorfa tallados por indígenas sobre pledra milenaria). El arte rupestre mokaná no está exento de la realidad comunicativa, su finalidad, preservar la memoria cultural de su tribu (mokaná). Tallaron sobre la roca expresiones significativas de la naturaleza; la realidad socio económica; mitos; su pensamiento abstracto y el modo de interpretar el mundo en que vivieron y actuaron. La iglesia de San Jose en Tubará es una edificación religiosa con rasgos de estilo neoclásico simple, mostrando una simetría en su concepción tanto en planta como en fachada. Está compuesta por una nave central y un presbiterio en el que se destaca el Retablo del arte barroco hecho en madera, recubierto

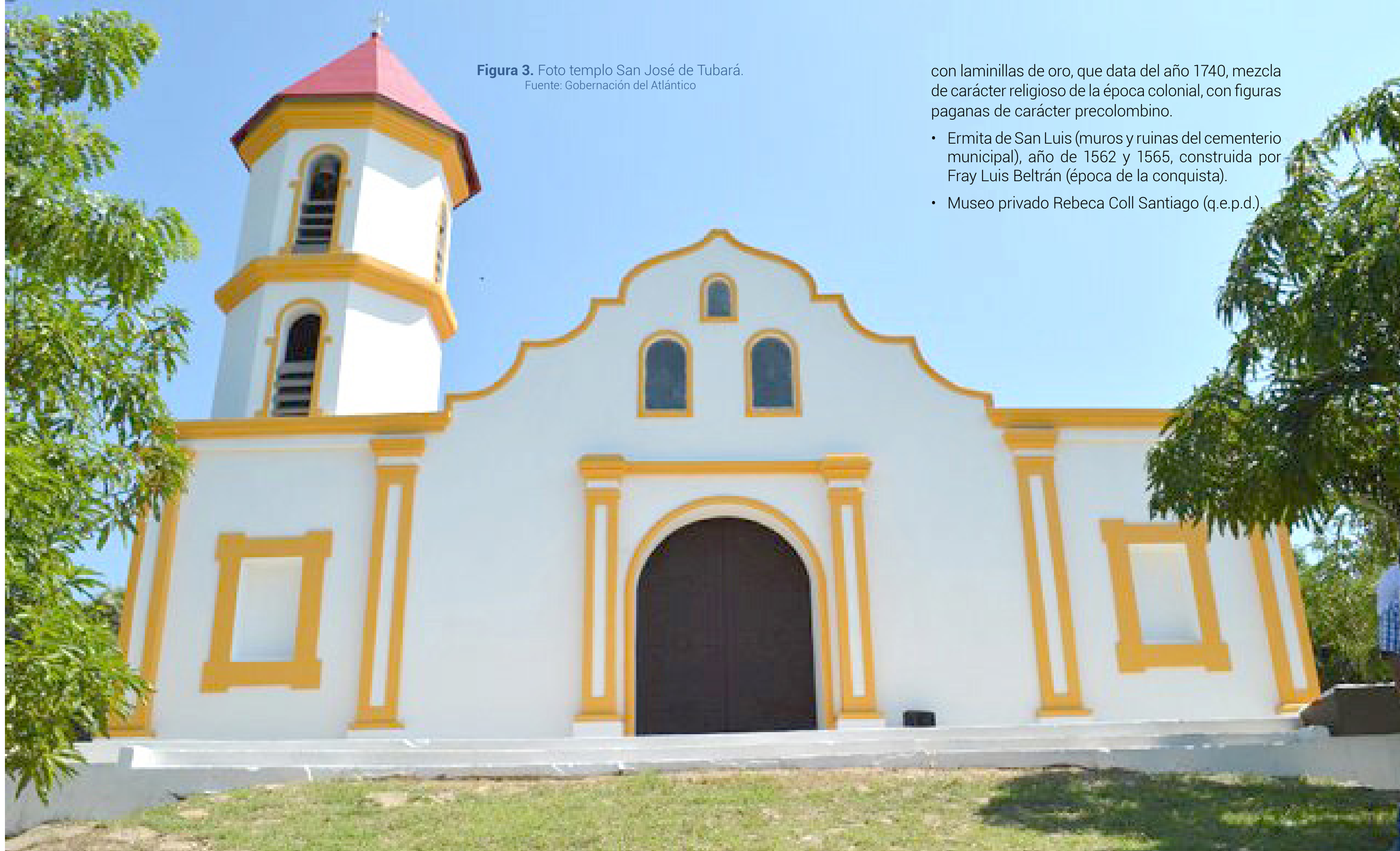



y este último crea el pueblo cerca de Tubará, con el nombre de Phión o Piojó en las estibaciones del cerro de la vieja (hace parte de la serranía de los montes de Maria), con una altura de 514 metros sobre el nivel del mar. Los corregimientos del Municipio de Piojó son: Ibácharo, Aguas Vivas y El Cerrito.

Eje Centro sentido Norte - Sur

Comprende el barrido de los municipios con sus respectivos corregimientos, localizados a lado y
lado de la carretera la Cordialidad: Municipio de Galapa( corregimientos de Paluato): Municipio de Baranoa (corregimientos de Campeche, Pital y Sibarco): Municipio de Sabanalarga (corregimientos de Aguada de Pablo, Cascajal, Colombia, Gallego, Isabel López, La Peña y Molinero); Municipio de Manatí (corregimientos de Las Compuertas): Municipio de Usiacurí: Municipio de Repelón (corregimiento de Villa Rosa, Cien Pesos); Municipio de (corregimientos de Arroyo de piedra, Santa Cruz. Los Péndales, Palmar de Candelaria y San Juan de Tocagua);

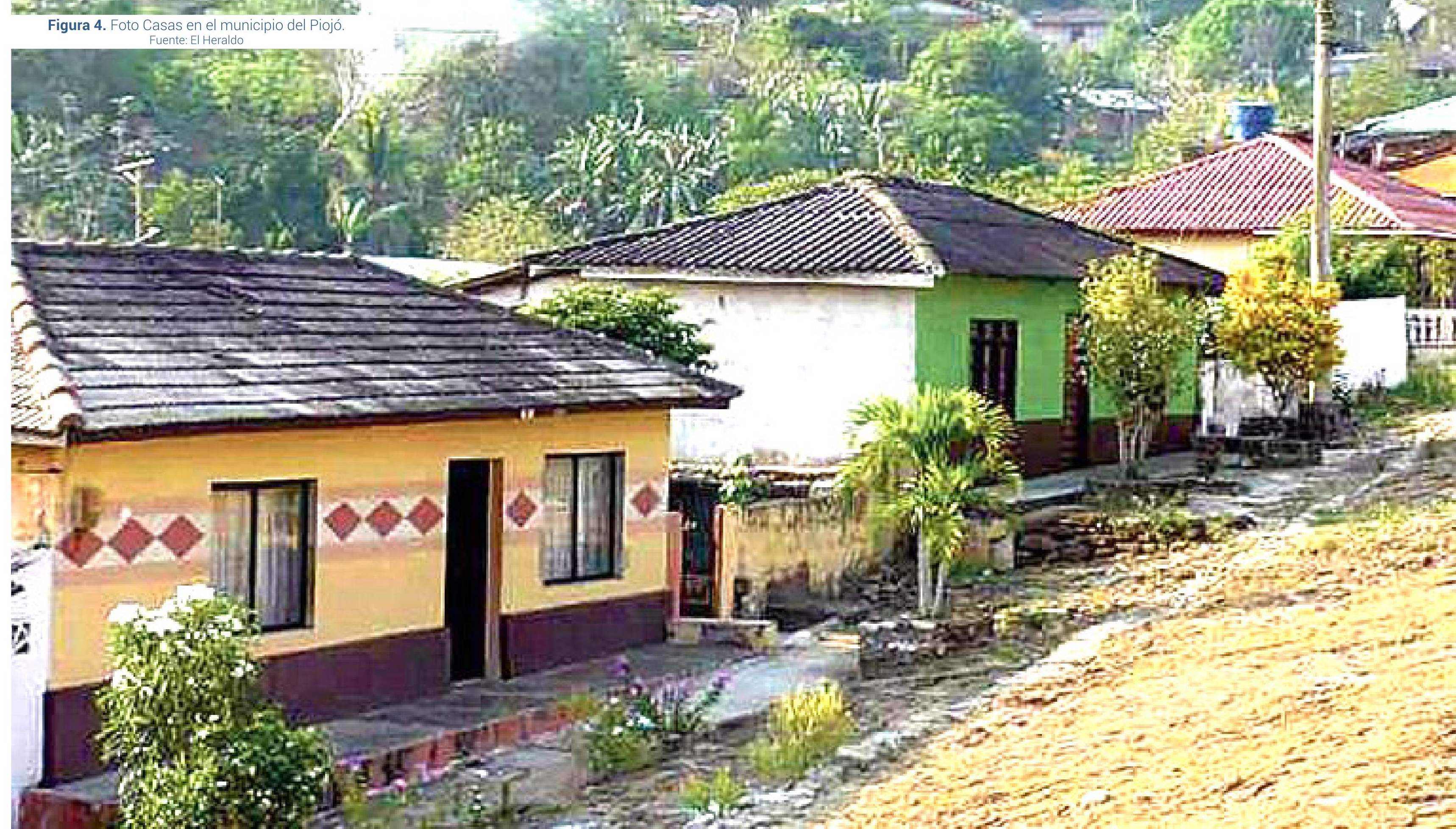


Su descubrimiento se remonta al año 1553 (es de (edro de Heredia. Este asentamiento indigena de la raza de los mokaná (mezcla de indios caribes y autoctonos), ya existía a la llegada de los españoles. Se creo como municipio por medio de la Ley 37 de 98 kms2 y $22 \mathrm{~km}^{2}$ de extensión urbana, situado a $8 \mathrm{~km}$ de distancia de la ciudad de Barranquilla (vía La Cordialidad).

\section{Municipio de Baranoa}

Esta población de origen indígena (tribus arawakcaribes), asentada a orillas del arroyo Grande, fue avistada en el año 1534 por Don Pedro de Heredia; refundada por los españoles con el nombre de Santa Ana de Baranoa. En el libro Baranoa indígena, escrito por el Licenciado Alberto Sarmiento, hace referencia al nombre de Baranoa, y expone que este puede ser una transliteración de las palabras arawak y paranawa, que traducen "Ios que viven detrás de los que no comen" Recibió la categoría de municipio en el año 1856. Comprende y Sibarco.

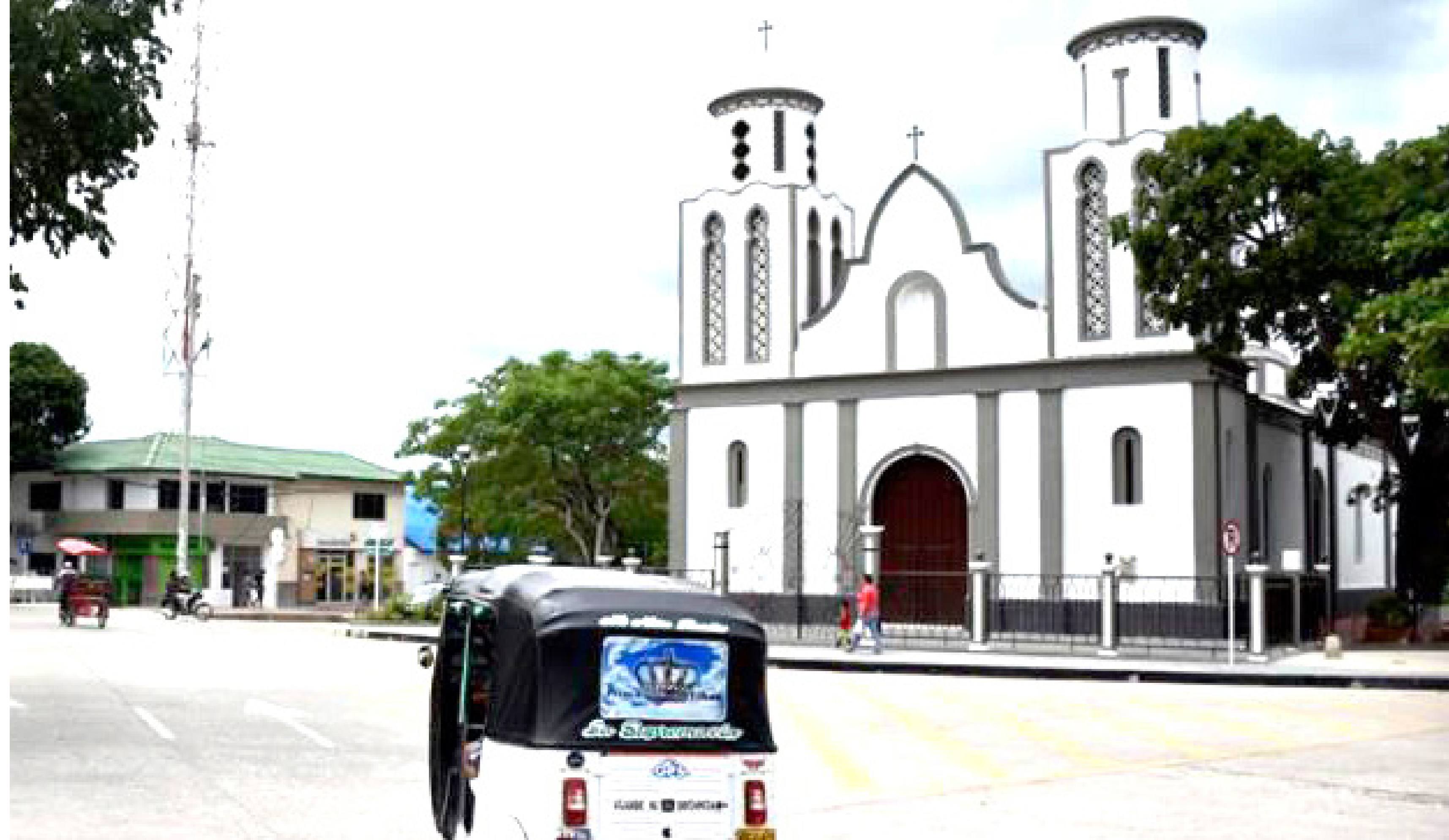




\section{Municipio de Sabanalarga}

Su origen data del año 1620. En el año 1680 fue elevado a la condición de corregimiento por el virrey Sebastián de Eslava. En el año 1744 empezó su vida en comunidad, conformando casa alrededor de una iglesia pajiza. En el año 1833 fue elevada a Villa, como capita del departamento del Atlántico. El municipio lo confoman los corregimientos de Aguada de Pablo, Cascajal, Colombia, Gallego, Isabel López, La Peña y Molinero Construcciones tipológicas de uso doméstico.

- Arquitectura funeraria

El cementerio municipal de Sabanalarga Atlántico, cuya construcción data de 1870, es decir aproximadamente 143 años, ocupa un lote de $16.150 \mathrm{~m} 2$ ubicado en el centro del casco urbano (calles 27 y $27 \mathrm{C}$ entre carreras 16 y 16B); está conformado por 1.540 bóvedas o sitios para sepultar cadáveres, distribuidos en 22 calles y 4 carreas, con una capacidad mayor a en 22 calles y 4 carreas, con

En la historia de Sabas. En la historia de Sabanalarga, ouentan como en siglos pasados debido a las bajas tasas de mortalidad los muertos eran sepultados en las iglesias, o patio de las viviendas, el camellon Arevalo o Parque Centra del municipio tambien fue sitio para las sepulturas, En a En la actualidad el cementerio de Sabanalarga muestra una estructura fisica deteriorada, como consecuencia de la falta de mantenimiento preventivo además un hacinamiento desbordado debido al au mento de la tasa de mortalidad, consecuencia directa del aumento vertiginoso de la población, enfermedades, violencia y accidentes.
Figura 6. Foto Parque cementerio de Sabanalarga.

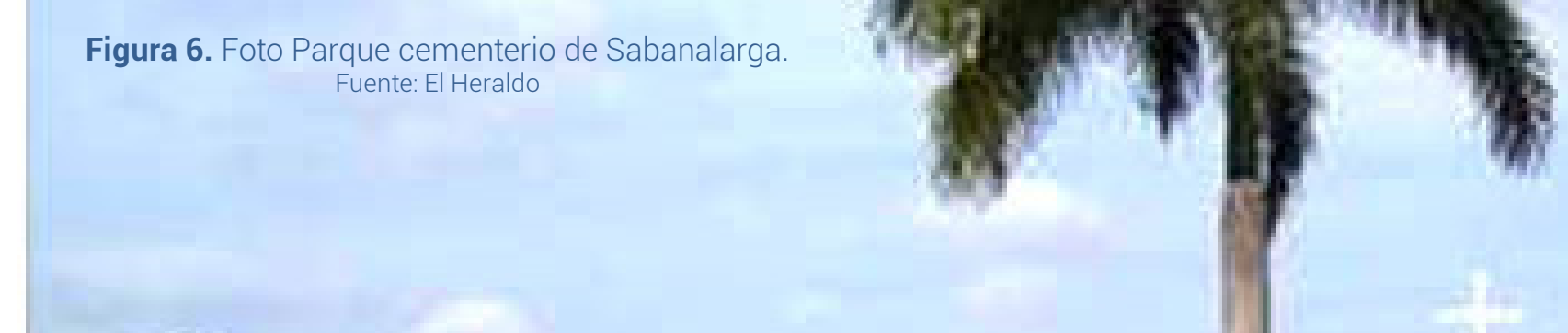

MN

-

(1)

I.

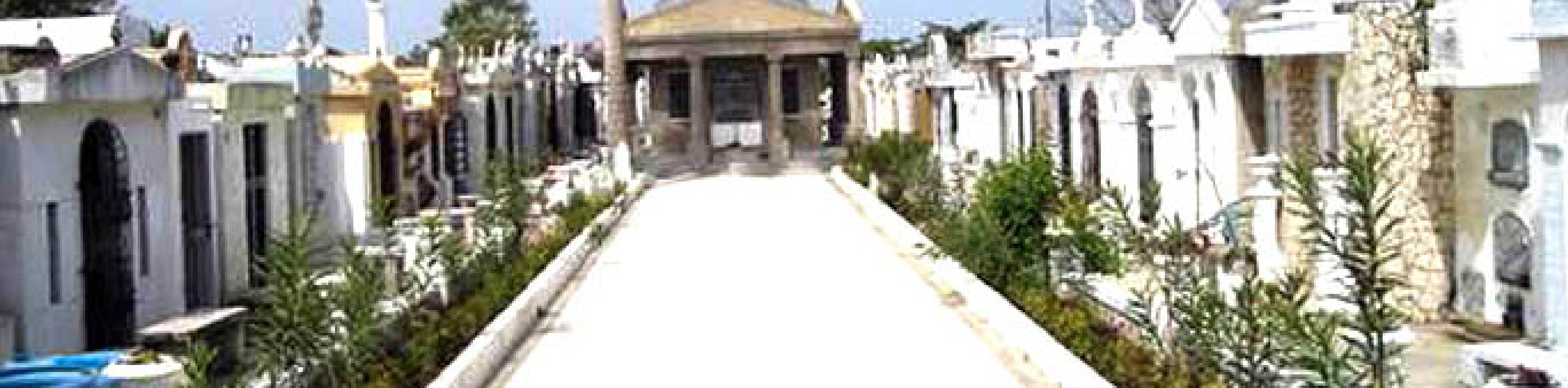

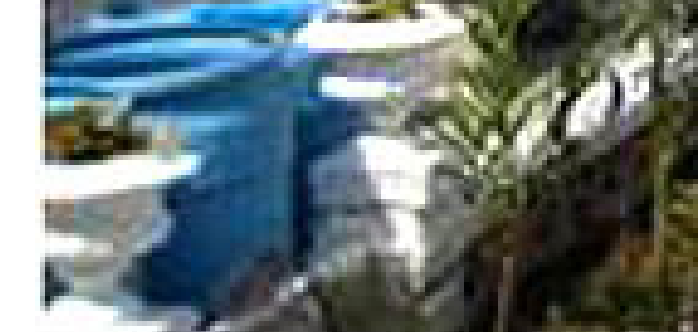

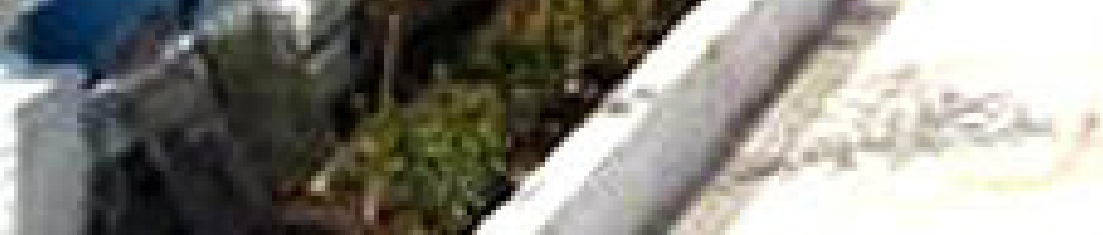

.

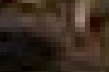

$2=$ 
Municipio de Usiacurí

Resguardo indígena de la costa norte colombiana (1533), de los pueblos más antiguos de la costa Atlántica. Declarado corregimiento en el año 1745 por el gobierno de Cartagena de Indias, y en el año 1856 elevado a la categoría de Municipio. Su nombre obedece a una combinación de los términos usía (señoría) y curí (nombre del cacique que habitaba el lugar). Localizado a $38 \mathrm{~km}$ de la ciudad de Barranquilla y 95 metros sobre el nivel del mar. este municipio tiene una extensión de $103 \mathrm{~km}^{2}$ y su área urbana ocupa sólo 0,3 km².

- Patrimonio Nacional

Casa Museo "JULIO FLOREZ" declarada Monumento Nacional y Patrimonio Cultural dela Nación por el Ministerio de Cultura, a través de la Ley 1126 de febrero de 2007. Esta casa museo es el sitio donde viviera y muriera el poeta Julio Flórez, quien llega a comienzos del siglo pasado en busca de salud y cura de una enfermedad que lo aquejaba, ya que los pozos de aguas medicinales (aguas sulfídicas) eran de notoriedad nacional y atraia a cientos de turistas en esa época. Estos pozos se constituyen en el factor determinante del desenvolvimiento historico y cultural del Municipio de Usiacurí (Martínez, 2010). En el año 2009 el Ministerio de Cultura incluye a la Casa Museo Julio Flórez en la lista de ejemplos nacionales de este género, durante el encuentro nacional de Museos desarrollado en la ciudad de Bogotá.

Figura 7. Foto Casa museo Julio Flórez en el municipio de Usiacuiti

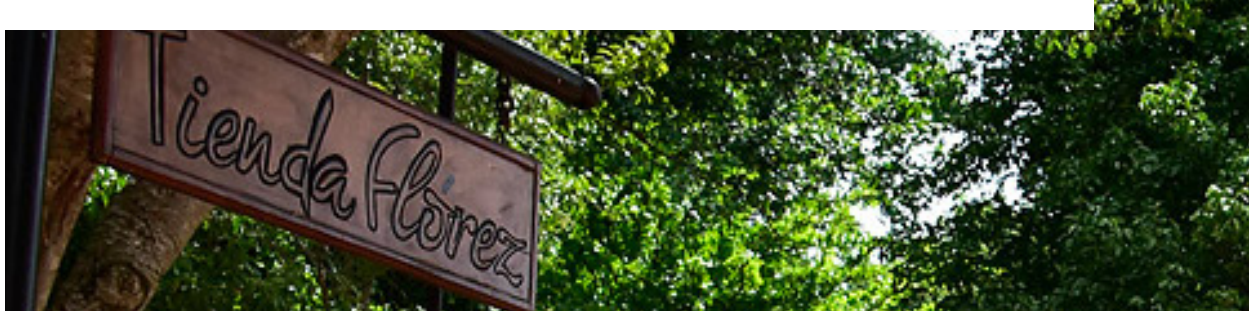

378

85

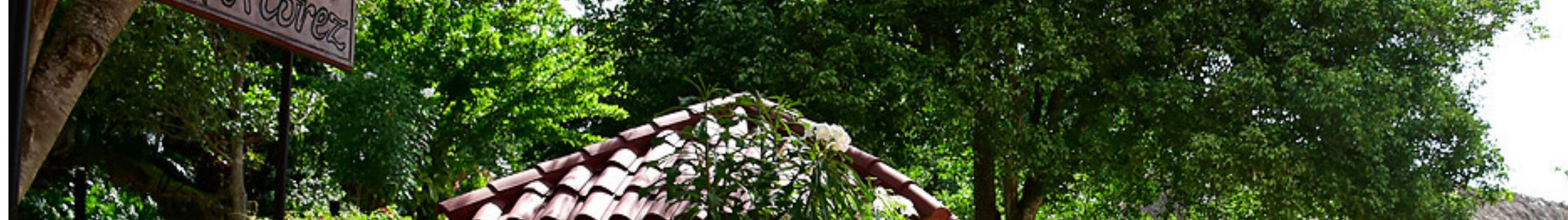

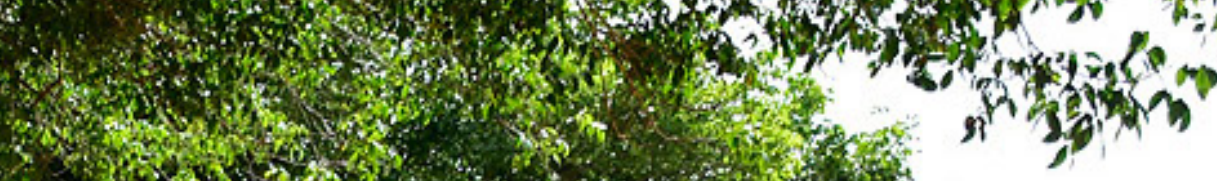
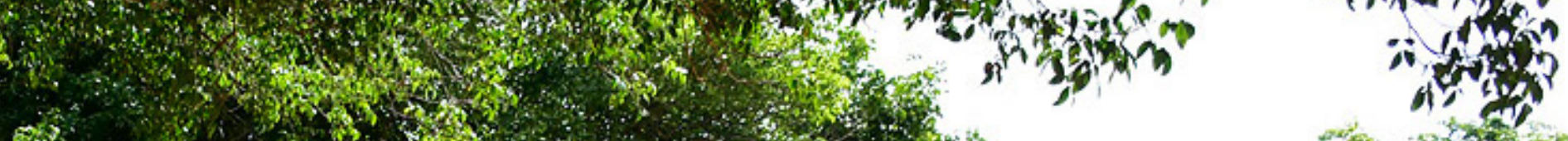

$3.2 \%$.

Tartame

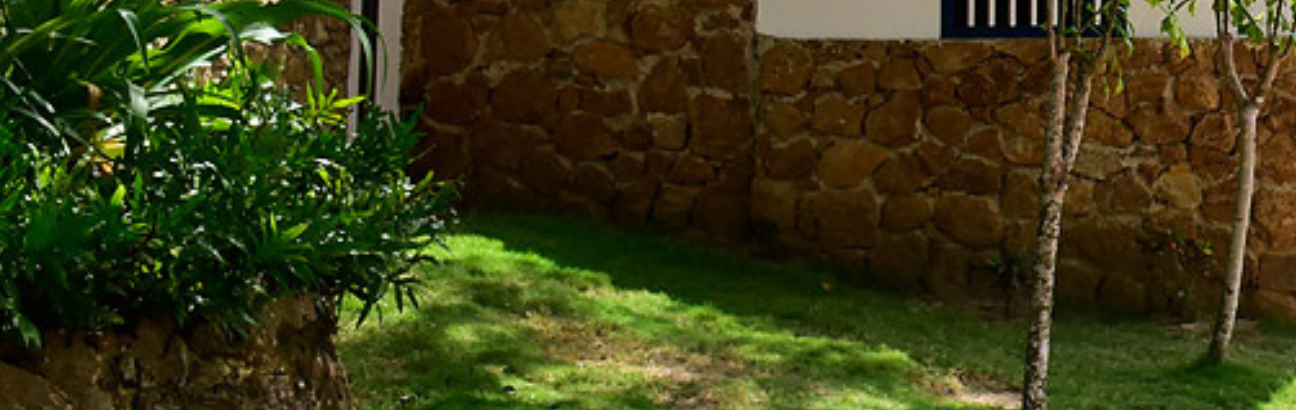
Tim:

政
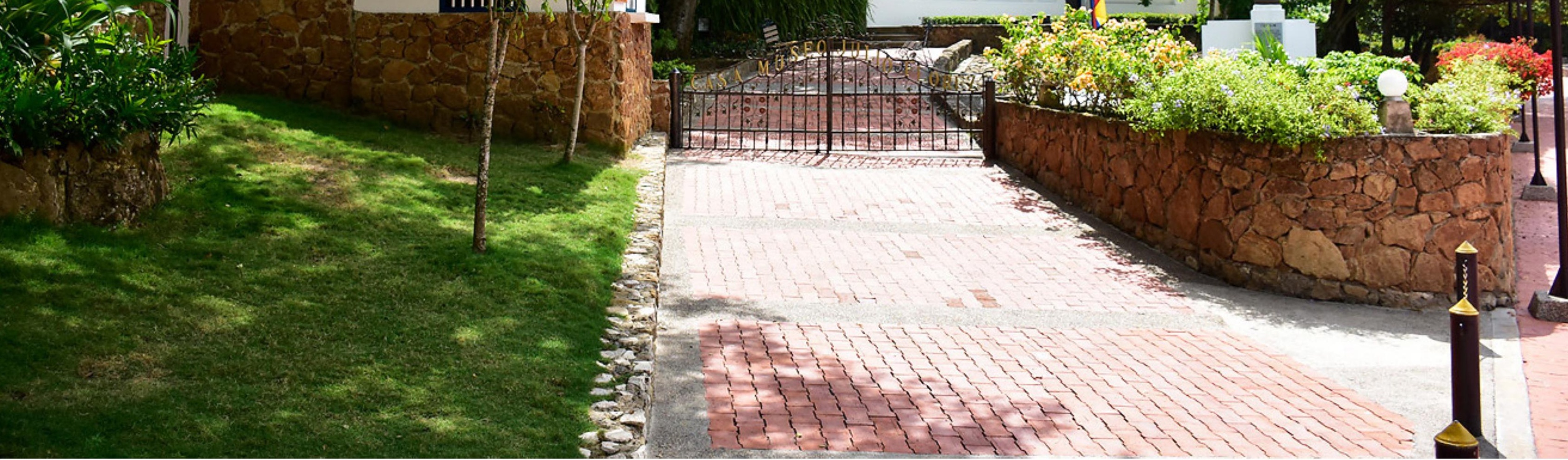
Situado al sur del departamento del Atlántico, creado en el año 1639, en un lugar que los nativos Ilamaban mahabana. Su cabecera municipal Manatí está localizada a $71 \mathrm{~km}$ de la ciudad de Barranquilla. El elemento arquitectónico patrimonial más importante es la Iglesia San Luis Beltrán, cuya construcción en su primera fase se inició en el año 1893, se terminó en el año 1926, y el año 1952 se adicionaron las torres estando a cargo el padre Basilio Natera. Otras construcciones patrimoniales de arquitectura doméstica están ubicadas en la calle 8 con carrera 8; Calle 8, carrera 5D; Calle 10, carrera $5 B$; Carrera 5B, calle 6 esquina.

\section{Municipio de Repelón}

El Municipio de Repelón está conformado por ocho (8) corregimientos; situado al sur occidente del departamento del Atlántico, en el territorio definido por el embalse del guájaro y la serranía del caballo. Su fundación data de octubre de 1848.

Según la tradición oral narrada por los pobladores antepasados se dice de la existencia de San Benito de las Palomas una población que sufrio desde el año 1650 cuando se dio la primera inundación de la zona del guájaro con la construcción del canal del dique, y las arremetidas en época de invierno tanto del Rio Grande de la Magdalena como de su derivación, los cuales dieron paso a la formación que llamaron ciénaga La Limpia, obligando a sus habitantes a buscar terrenos más altos para reubicarse.

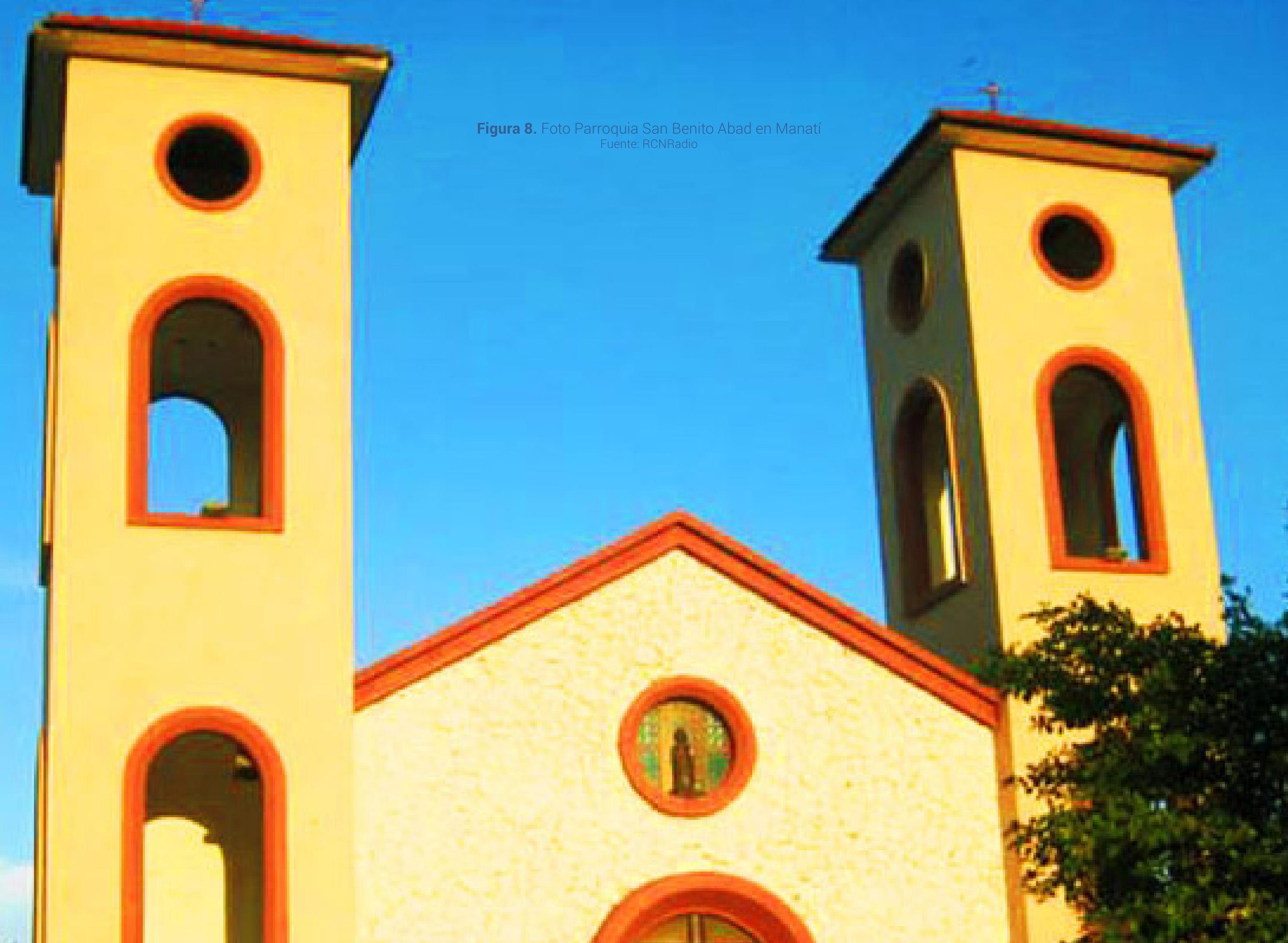


De esta manera los habitantes de San Benito de las Palomas emigraron a los sitios más altos donde hacían sus cultivos, cada familia que llegaba acondicionaba el lugar donde construía su vivienda a lo que llamaban un Repelón, así cada uno fue haciendo su Repelón dando origen al Municipio. Hasta la fecha no se ha realizado una investigación arqueológica de la zona donde estuvo situada la población original San Benito de las Palomas, de la cual se divisaban desde las orillas de la Ciéne de los horcones de la estructura de la lglesia y algunas construcciones ubicadas en pequeños montículos pero en el año 1967 se perdió toda mosibilidad pero en el año 1967 se perdí toda posibilidad a quedar la zona completamente inundada con

En el recorrido por el municipio de Repelón nos

detenemos en el Corregimiento de Villa Rosa por

ser el de mayor extensión (13200 hectáreasa, de

cuales 6.010 corresponden al embalse del gúáaro

en el cual a diferencia de los otros corregimientos

encontramos una vivienda que llama la atención

por sucaracterístico diseñoy sistema construction.

- Casa Patrimonial en Calle Central

Granero Central de Villarosa)

Ubicada en la esquina de la calle central (calle 6), con carrera 7, construida por un maestro de construcción cartagenero de apellido Martelo, con las características de las viviendas de la población de Arenal (Bolívar), por encargo del señor Tomás Alvear Narváez y su esposa señora Gilma Utria Rodríguez en el año 1908. La población Villa Rosa lleva el nombre de la hacienda en donde fue cons-

Figura 9. Foto Antigua Plaza de mercado en Repelón
Fuente: RCNRadio

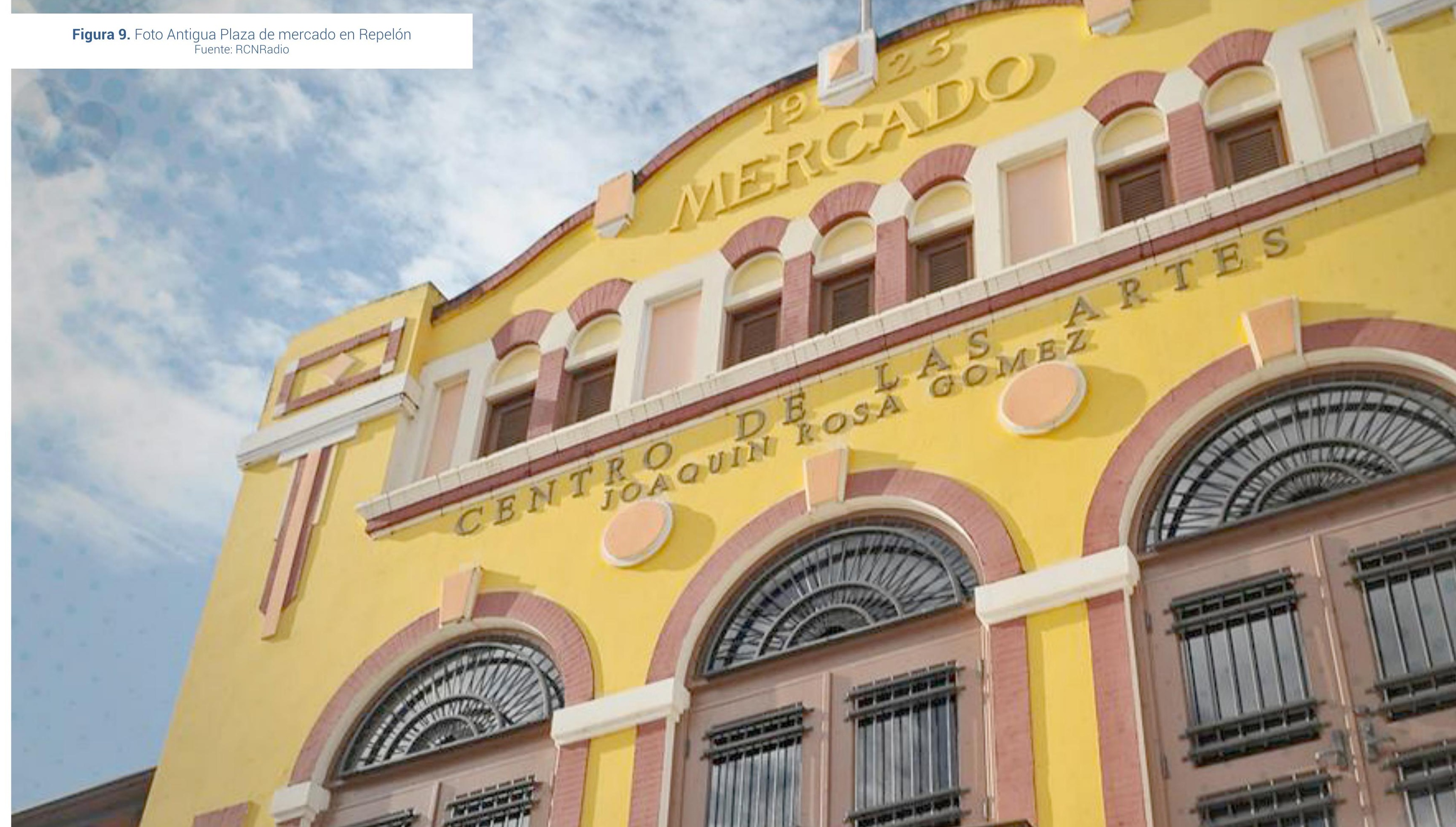


truida esta edificación, por lo cual su valor patrimonial es reconocido por los pobladores de la misma. Es la Edificación con mejor calidad edificatoria conservada en el corregimiento y el municipio, por lo cual la Gobernación del Departamento del Atlántico, a través del Consejo departamental de cultura y patrimonio está gestionando su Restauración, para convertirla en el Museo etnológico de Villa Rosa. Identificada con el No. $6^{\mathrm{a}}-52$ de la Carrera 7.

\section{Eje Oriental: Acera Norte - Sur}

Comprende el barrido a lo largo de la carretera oriental, iniciando en el Municipio de Soledad (población conurbada con la ciudad de Barranquilla); Municipio de Malambo (corregimiento de Caracolí); Municipio de Sabanagrande (no tiene corregimientos); Municipio de Santo Tomás (El Uvito); Municipio de Polonuevo (corregimiento de Pitalito); Municipio de Palmar de Varela (corregimiento de Burrusco); Municipio de Ponedera (No tiene corregimientos); Municipio de Candelaria; Municipio de Campo de la Cruz; Municipio de Suan; Municipio de Santa Lucía (corregimiento de Algodonal).

\section{Municipio de Soledad}

El Municipio de Soledad fue fundado el 8 de marzo de 1598 por el Capitán Antonio Moreno y Estupiñán. El antiguo sitio denominado la porquera de San Antonio logró la categoría de parroquia en el año 1743, y en el año 1813 se le concedió el título de "Villa", con el nombre de Soledad de Colombia. Población situada a tres (3) kilómetros de la ciudad de Barranquilla, se- parada por el arroyo Don Juan; y a 5 metros sobre el nivel del mar, es un territorio conurbado con el distrito de Barranquilla.

La Iglesia San Antonio de Padua localizada en el municipio de Soledad, en el barrio Centro, resume y condensa todo el saber técnico de un momento determinado de la historia, aplicado en su construcción; caracterizada por la sencillez de su fachada simétrica y con dos Torres que enmarcan un frontis de conformación triangular coronado por seis pináculos, es declarada por el Congreso de la República, en el año 1999, como Monumento Nacional, según Ley 532 del mismo año (Martínez, 2011).

El Municipio de Soledad cuenta con un Museo Bolivariano - Casa de Bolívar, donde habitó el Libertador Simón Bolívar días antes de su muerte. Se describe como una casa tipo colonial que en un principio era propiedad de Pedro Juan Visbal. Esta se encuentra ubicada en la cabecera municipal, a pocos metros de la Iglesia central de Soledad. La Casa de Bolívar de Soledad fue declarada Monumento Nacional según Acuerdo 039 de 1970 y Museo Bolivariano de Soledad según fecha 08 de marzo de 2005 emanada por el Concejo Municipal de Soledad. Es una edificación construida en dos (2) niveles desde donde el turista puede apreciar cuadros pictóricos y documentos que narran la vida y obra del libertador Simón Bolívar

El mercado público de Soledad se encuentra ubicado sobre la margen oriental del municipio, a orillas de un brazo del río grande de la Magdalena, tiene 102 años de antigüedad, cuenta con un puerto de trasporte fluvial que abastece a la población y supermercados de la ciudad y el distrito de Barranquilla, con pro- 
ductos agrícolas de pan coger que hacen parte de la canasta familiar, en donde predominan las hortalizas, legumbres y frutas propias de nuestra región.

El Aeropuerto de Soledad se encuentra ubicado en el municipio de Soledad sobre la margen oriental del Departamento del Atlántico a 5 kilómetros de la cabecera municipal y presta sus servicios la ciudad de Barranquilla y municipios aledaños. En el año de 1936 comenzó a a operar con una pista asEn el año de 1936 comenzo a operar con una pista aspacho y recibo de carga y pasajeros. Hoy es uno de los pacho y recibo de carga y pasajeros. Hoy es uno de los terminales aéreos más importantes de America del Sur. 2.3.2 Municipio de Malambo: Fundado por indigenas mocana bajo el mando dé cacique Pedro Malambo (nombre tomado de unos árboles bastante abundante de la región a la llegada de los españoles en el año 1529, comandados por Jerónimo de Melo.

En 1533 el Conquistador Don Pedro de Heredia Ega a Malambo y queda extasiado con las areda nís en barro elaboradas por los habitantes indígenas Esta población abundante exigía su evangelización, cua estuvo a cargo de San Luis Beltrán bajo la en, mienda de Alfonso López Ayalo de 1562 a 1569 . Debe resaltarse que Mambo fue la tercera encomienda en importancia en Tierra Adentro Se estima que después de Cartagena y Mompox Malambo es la comunidad más meritoria del antiguo estado de Boĺvar En 1857 es elevado a distrito municipal pero, más tardes 1885, desciende a la categoría de corregimiento pesar de ello, fue erigido municipio en 1912 . Con pesar de ello, fue erigido municipio en 1912. Con una de Barraula es uno de los cuatro municipics hacen parte del área Metropolitana de Barranquilla.
Figura 10. Foto aérea del municipio de Soledad.

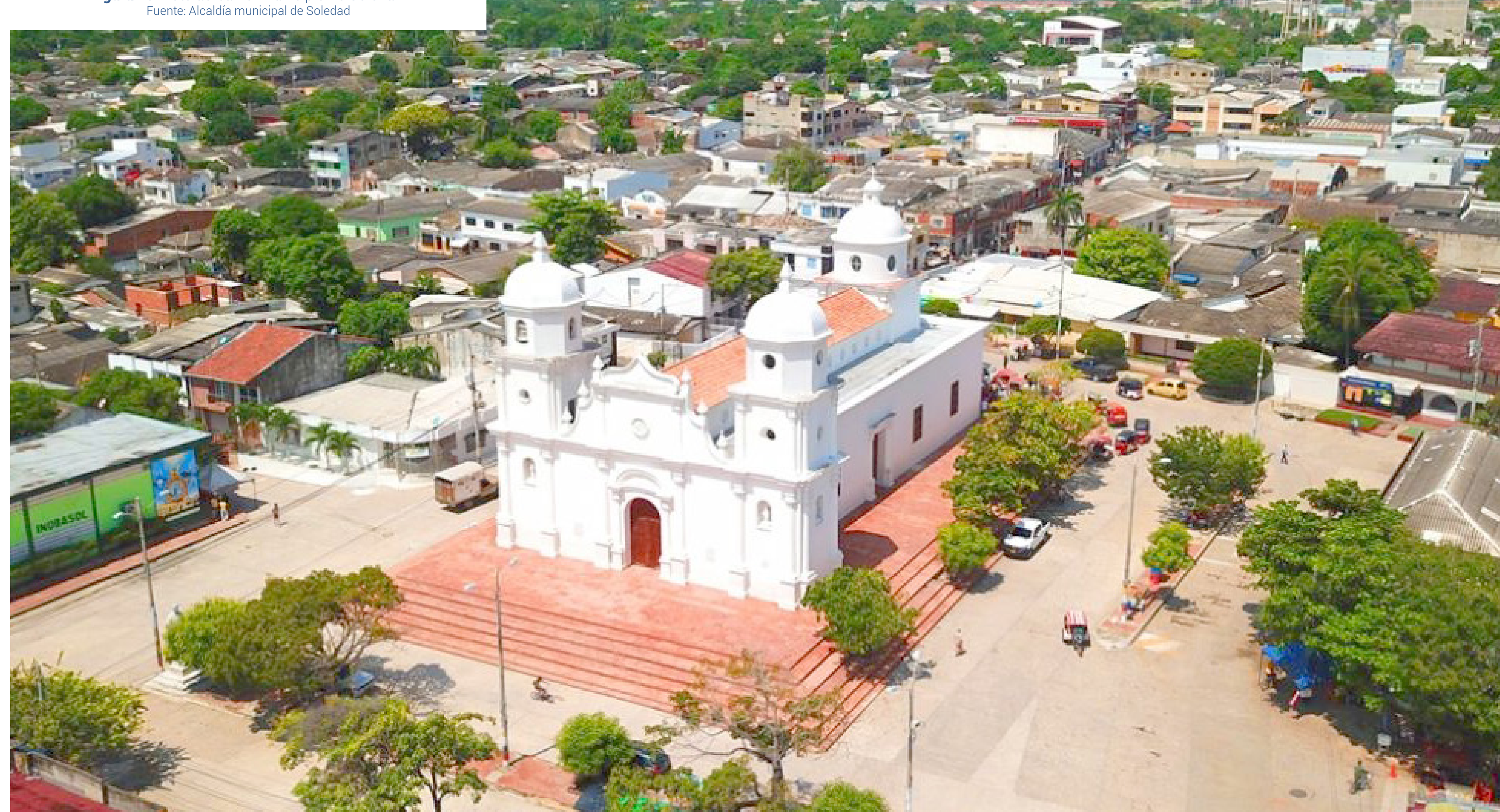




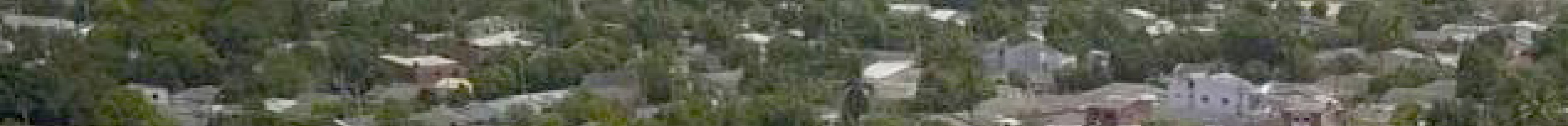

\section{Municipio de Sabanagrande}

La población comenzó a formarse en el año 1620 según estudios del investigador José Agustín Blanco, en la cual se afirma que su fundación se debe a inmigración de personas de diferentes razas, como consecuencia de las inundaciones producidas en el caserío llamado Villa de San José, hoy municipio de Sitionuevo. Sabanagrande fue fundado en 1704 por Francisco Camacho; elevado a la categoría de municipio en el año 1857.

\section{Municipio de Santo Tomás}

Fundado a principios del siglo XVIII (1543) por Francisco y Miguel Becerra. Este asentamiento ribereño fue erigido en municipio en junio de 1857; Sede de la capitanía de guerra de Tierradentro durante el período colonial.

Santo Tomás es un municipio situado a $25 \mathrm{~km}$ de la ciudad de Barranquilla; posee una población de 34.200 habitantes y $66 \mathrm{kms} 2$. Su principal manifestación cultural son las fiestas del carnaval, y su Reinado intermunicipal y la Batalla de Flores fueron declaradas Patrimonio Cultural de la Nación en el año 2011, mediante Ley 1353, del Congreso de la República.

\section{Municipio de Palmar de Varela}

Fundado en 1762 por Catalino Varela. El caserío era rico en un tipo de palma llamada palmiche o palma rico en un tipo de palma llamada palmiche o palma real, lo que dio origen al nombre del municipio. Palmar de Varela municipio segregado del municipio de

\section{Figura 11. Foto aérea del municipio de Santo Tomás.}

\section{.}

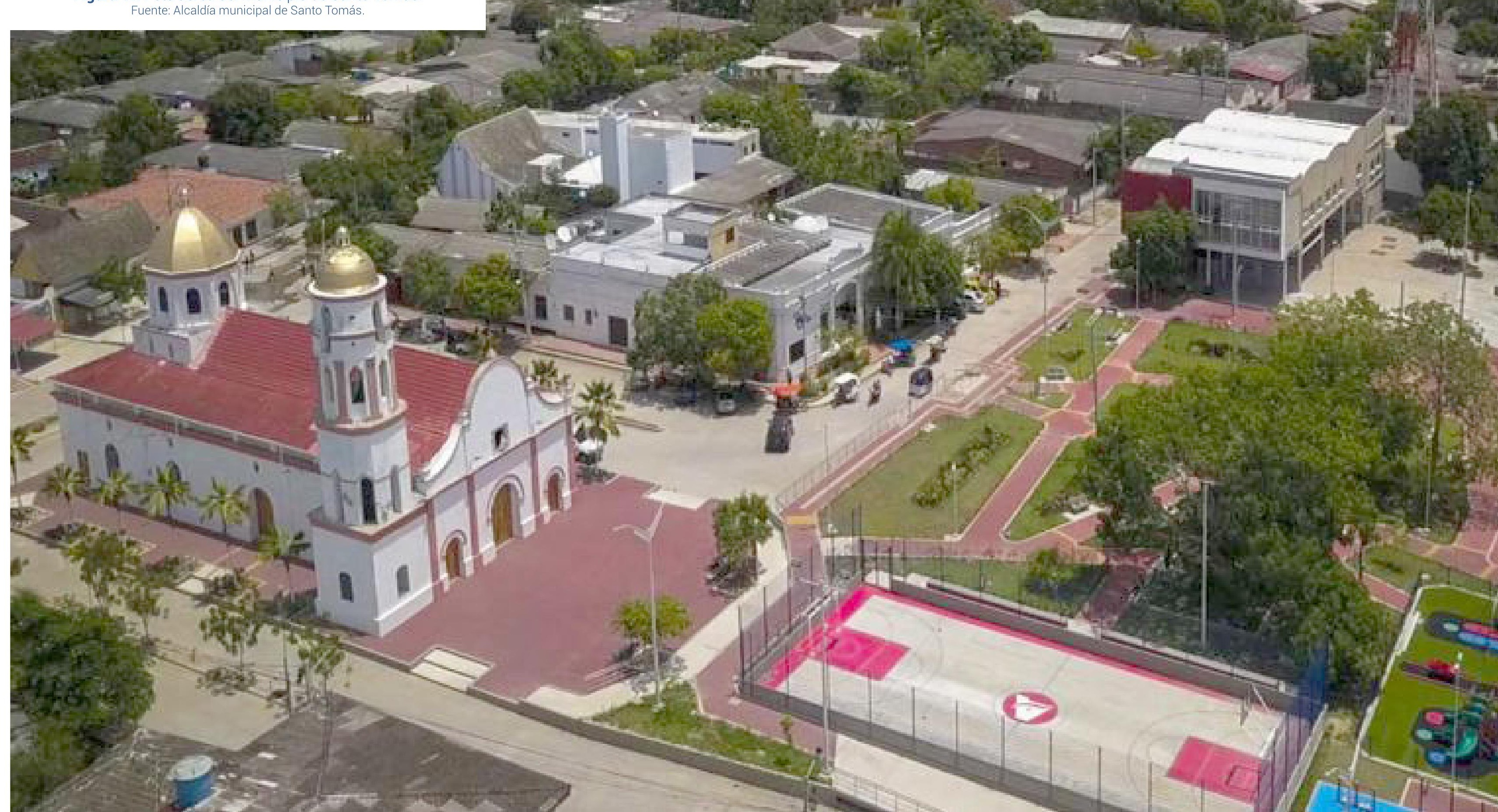




\section{Municipio de Ponedera}

Su fundación data de 1743, por Don Francisco Pérez de Vargas, reconocida como municipio en 1965; su verdadero nombre es San José de Puerto Alegre, pero ha primado el apodo de Ponedera, en razón de que a las playas que dejaba el Rio Magdalena en época de sequía, llegan cantidades de hicoteas, iguanas y tortugas a desovar.

\section{Municipio de Candelaria}

Fundado en el año 1681 por los hermanos Domingo y Manuel Caraballo descendientes de españoles. Su nombre proviene en honor a la Virgen de la Candelaria. Antes habia tenido los nombres de Corral de piedra, por lo pedregoso de su terreno, y posteriormente el nombre de Tasajera, que era el sitio para tasajear y salar la carne vacuna. Sus corregimientos son: San Buenaventura de Leña y San José de Carretal.

Municipio de Campo de la Cruz

Población fundada en los tiempos de la colonia (1634) por una familia española de apellido Melga(1634) por una familia española de apellido Melgarejo. Los pobladores le dieron el nombre de Puerto Real de la Santínina Cruz, posteriormente quedó Durame la Colonaz principios de este siglo. Durante la Colonia el municipio pertenecía a la provincia de Cartagena de Indias, bajo el mando del virrey Don Antonio Caballero y Gongora. En el año 1772 funcionó como la segunda capitanía del partido de Tierradentro hasta 1810. Campo de la Cruz fue varias veces cuartel general de los republicanos
Figura 12. Foto Catedral del municipio de Candelaria.
Fuente: Periódico El Sol.

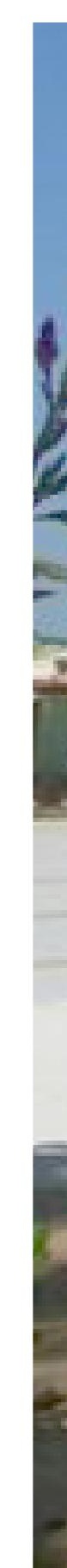

e 17 , bes

,

x

Wes
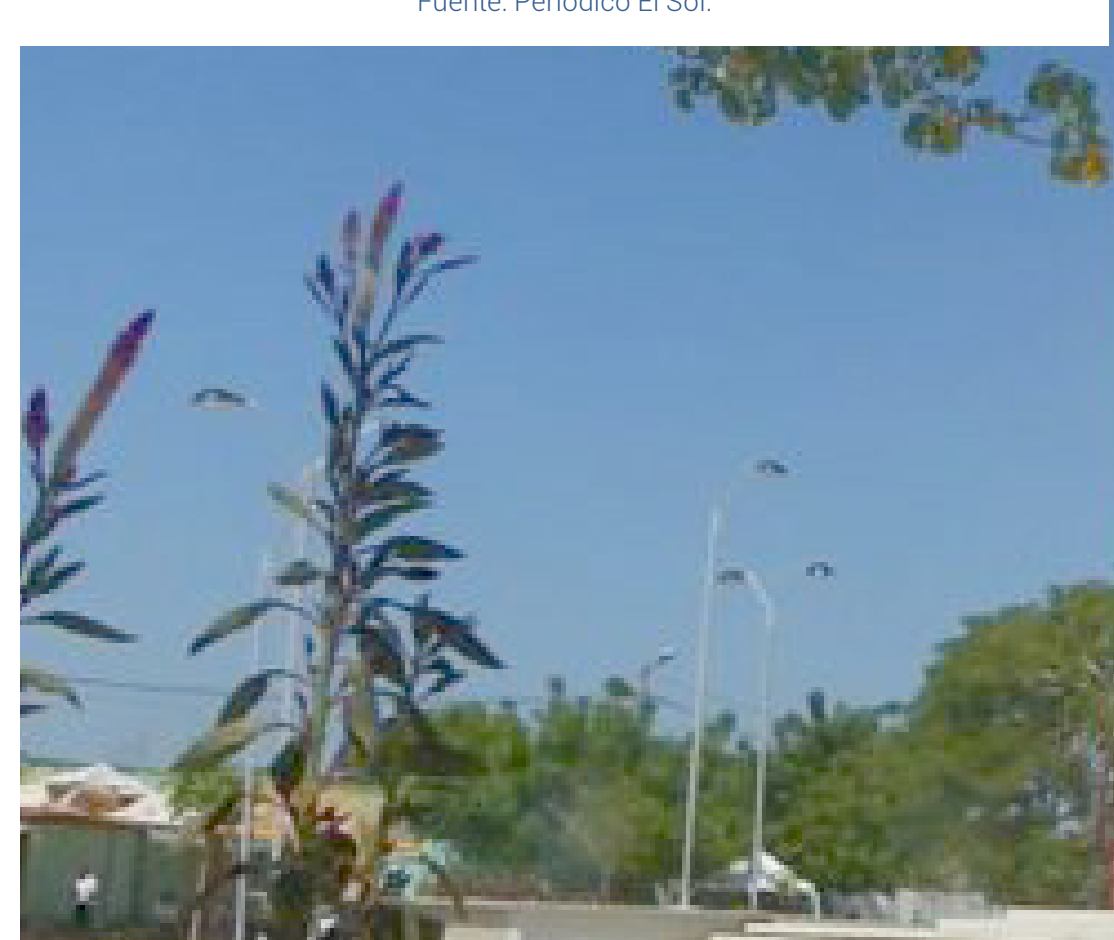

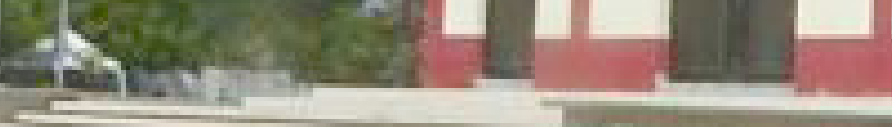

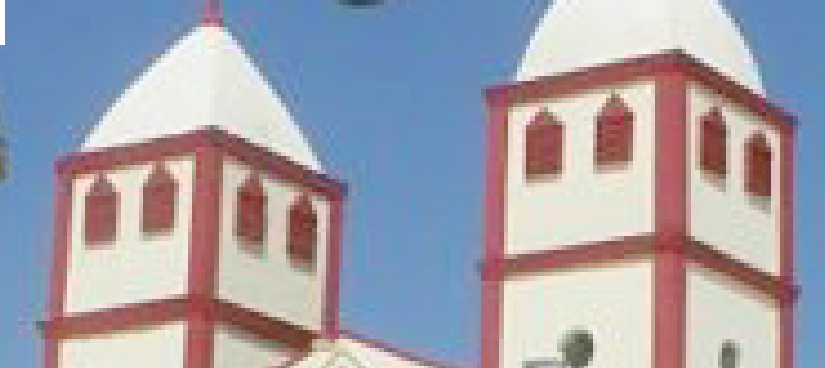

颌而

in

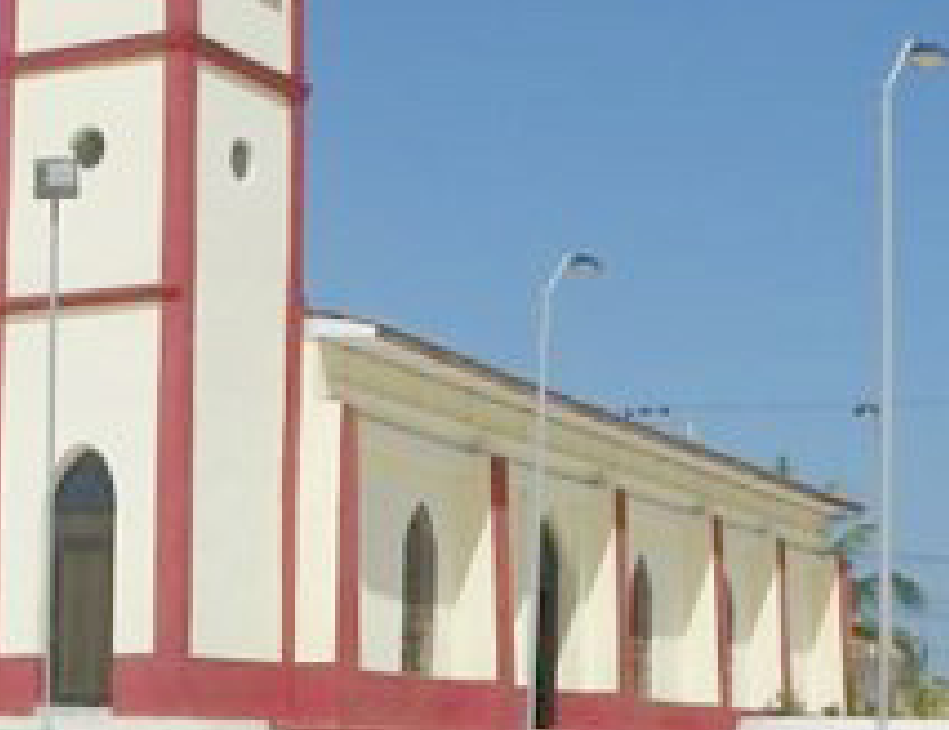

$\underline{\underline{E}}$

then

(n)

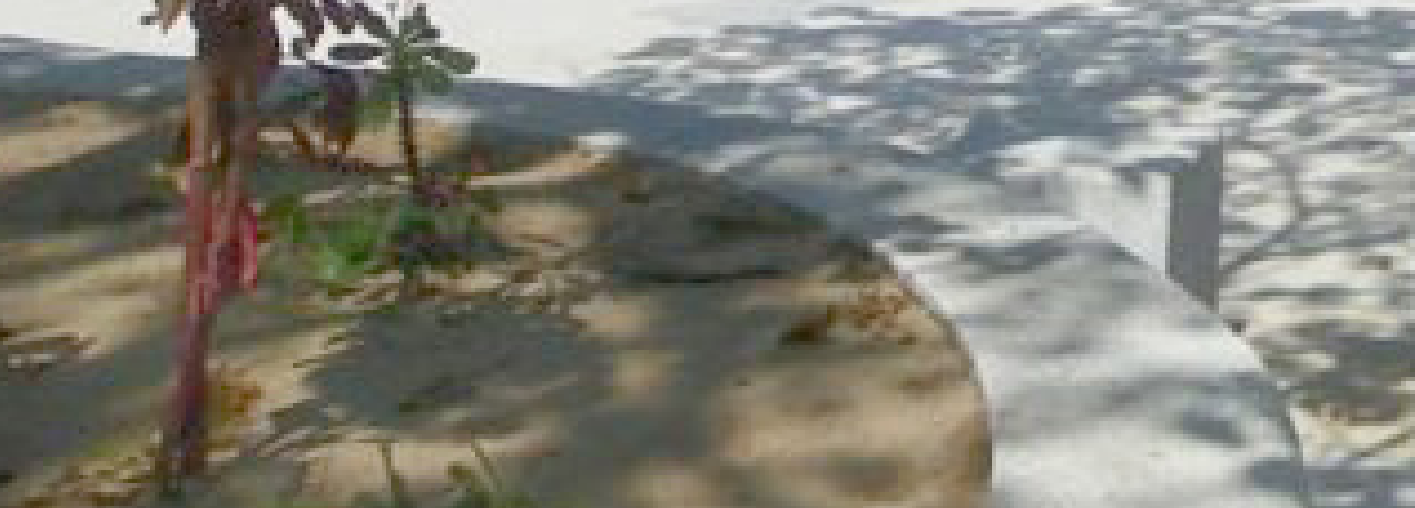

(1)

vis ath 
El municipio fue creado en el año 1914 y de él se segrego el municipio de Santa Lucía. Sus fiestas patronales son las Fiestas de San José patrono del pueblo.

Las viviendas en Campo De la Cruz mantienen rasgos coloniales en los alrededores de la Plaza es decir muestran una arquitectura marcada por la influencia española. En las manzanas alejadas de la Plaza se presentan una variedad de viviendas construidas con base en la arquitectura vernácula tínstruidas con base en la arquitectura vernácula tipica y propia de los pueblos del departamento rasgos arquitectónicos eclécticos de origen prehispánicos.

\section{Municipio de Santa Lucía}

Municipio ubicado al sur del departamento del Atlántico, a la margen derecha del canal del Dique Fundado en marzo de 1874 por la Sra. Luisa Guerrero Hormanza, natural de Cartagena (Bolívar), quien residía en Campo de la Cruz y salió de esta localidad a buscar aqua para su ganado debido a la tremenda sequía que azotaba a la región, encontrando en este sitio un canal, que hacía parte de canal del dique viejo que no se secaba y nacía en la bahía oriental del Rio Magdalena.

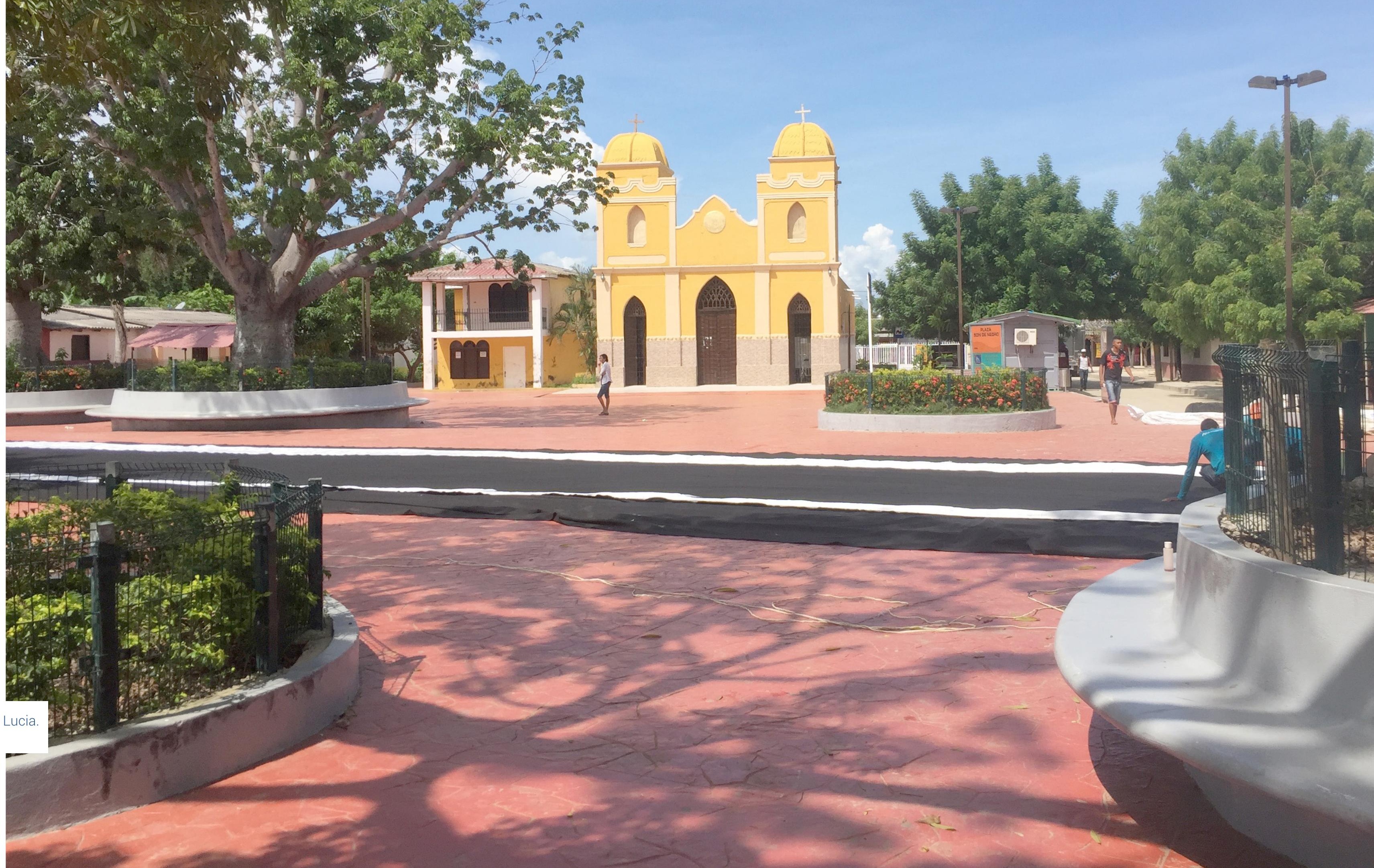




\section{ConClusiones}

El estudio de los antecedentes arquitectónicos patrimoniales en el departamento del Atlántico busca la transferencia de conocimientos especializados a la comunidad sobre la conservación de sus inmuebles; constituyendo así una propuesta para el tratamiento del complejo tema de la rehabilitación integral y/o restauración, aplicada no sólo a las edificaciones mismas en sentido particular, sino también a los centros de interés histórico y tradicional a nivel departamental

El trabajo realizado permite llegar a algunas conclusiones parciales y/o recomendaciones en relación con el proceso seguido y los próximos pasos que pudieran llevarse a cabo: Una limitación deriva de la escasez de experiencias previas y programas institucionales para profundizar las tareas relativas al descubrimiento de edificaciones arquitectónicas patrimoniales en las poblaciones más alejadas dentro del departamento del atlántico. El apoyo de un grupo de semillero de investigación con mayor número de participantes se hace fundamental, ya que los procesos de valoración suponen la necesidad de recurso humano capacitado técnicamente.

En líneas generales, los estudios realizados han constituido una experiencia positiva, se ha logrado observar una respuesta entusiasta y una amplia disposición por parte de las diferentes comunidades en los pueblos, con respecto a llevar a cabo planes de rescate de sus edificaciones patrimoniales.

Las interacciones entre la comunidad y el equipo de trabajo se pueden calificar de manera positiva.
Sin embargo deben apuntalarse el nivel del lenguaje y las estrategias de comunicación para promover la comprensión de los temas tratados sobre patrimonio y conservación de inmuebles patrimoniales en la participación de talleres.

Intencionalmente, los procesos mismos de identificación buscan transformarse en un instrumento dinamizador de la comunidad, estimulándola a adelantar planes de acción y organización para solicitar a la autoridad competente tener en cuenta las edificaciones y sectores patrimoniales dentro de los planes a que se hacen meritorios estos inmuebles. La participación colectiva de los propietarios de los inmuebles patrimoniales y habitantes de los sectores con características tipológicas en talleres, deberán contribuir a formular los planteamientos y propuestas, constituyendo un elemento determinante del proceso.

Lamentablemente, la variable económica de los propietarios de los inmuebles por lo general representa un freno a los procesos de mantenimiento de los inmuebles patrimoniales en los municipios del departamento del Atlántico, por lo que es necesario presentar propuestas de estos Bienes inmuebles de uso doméstico candidatos a ser declarados Bienes de interés Cultural del Departamento, en los consejos de Cultura y Patrimonio del Departamento.

La confianza está puesta en que la labor realizada, y lo mucho que aún queda por realizar, sirva para la Valoración, Conservación y Rehabilitación del patrimonio edificado en el Departamento del Atlántico, y de manera real coadyuve a alcanzar mejores condiciones de vida para sus habitantes. 
Las recomendaciones se basan en las necesidades y perspectivas de desarrollo que puedan asegurar un equilibrio entre el desarrollo económico de las poblaciones del departamento del Atlántico y la protección de su patrimonio arquitectónico; La Sensibilización de la población para la protección del patrimonio arquitectónico construido; Señalización en las vías de las rutas de los itinerarios, y el Reforzamiento de la actividad turística, combinando turismo cultural y ecoturismo. Además se deberán crear Centros de recepción de visitantes y promoción de los proyectos.

El estudio en sus fases futuras deberá considerar las problemáticas del patrimonio inmueble, como son el Deterioro físico y social de las edificaciones y sectores; la Inadecuada articulación y equilibrio entre el patrimonio inmueble y el desarrollo de la ciudad actual, entorno urbano y entorno ambiental; y por último los Procesos de deterioro evidentemente causados por la dejadez de los propietarios.

\section{REFERENCIAS}

Martínez, J. (2011). Iglesia San Antonio de Pauda (Soledad-Atlántico). Historia y Elementos para su Restauración Integral. Módulo ARQUITECURA-CUC, 10(1). 33-54.

Martínez, J. (2010). Plaza de la Casa Museo "Julio Flórez" en el municipio de Usiacurí, departamento del Atlántico. Módulo ARQUITECURA-CUC, 9(1). 71-85.
Ovalle, V. (julio, 2012). Muelle de Puerto Colombia: 120 años de historia. Fundación - Magdalena. Recuperado de http://fundacionmagdalena. blogspot.com/2012/07/muelle-de-puertocolombia-120-anos-de.html

Palacio, B., Esquivel, E., Quimbayo, M., Pacheco, A., Martínez, A. y Pégolis, J. (2011). Análisis estético de inmuebles de interés cultural ubicados en el municipio de Puerto Colombia, Atlántico. Revista Módulo, 10(1). 169-185.

República de Colombia. Ministerio de Cultura. (2009). Compendio de Políticas Culturales. [Documento de discusión]. Recuperado de http://www.mincultura.gov.co/SiteAssets/ documentos/Despacho/CompendioPoliticasCulturales_web.pdf

República de Colombia. Congreso de la República. (12 de marzo de 2008). Por la cual se modifica y adiciona la Ley 397 de 1997 -Ley General de Cultura- y se dictan otras disposiciones. [Ley 1185]. DO: 46929.

República de Colombia. Congreso de la República. (7 de agosto de 1997). Por la cual se desarrollan los artículos 70, 71 y 72 y demás artículos concordantes de la Constitución Política y se dictan normas sobre patrimonio cultural, fomentos y estímulos a la cultura, se crea el Ministerio de la Cultura y se trasladan algunas dependencias. [Ley 397].

República de Colombia. Asamblea Nacional Constituyente. (1991). Constitución Política de Colombia. Recuperado de http://www.secretariasenado.gov.co/senado/basedoc/ constitucion_politica_1991.html 
Tello, M. (2013). El proyecto de conservación integral del patrimonio inmueble: Enfoques conceptuales, reflexiones valorativas y apuntes metodológicos para la sustentabilidad integral del patrimonio inmueble. Módulo ARQUITECURA-CUC 12(1). 99-130.

Tello, M. (2008). Paisajes e Itinerarios Culturales como Estrategias para el Desarrollo. II Encuentro Internacional de Restauradores sin Fronteras A-RSF. Bogotá, D.C.: Scala.
Jairo Lopez Martinez es Magister en Educación de la Universidad de la Costa (Colombia) con especialización en Arquitectura y especialización en Ciencias Sociales y Humanas de la Universidad de la Costa (Colombia). 